\title{
PVD Coatings Influence (TiCN, BCN and CrAIN) on the Fatigue Life Behavior of AISI 1045 Steel for Automotive Applications
}

Juan Francisco Correa ( $\nabla$ jfcorrea@espe.edu.ec)

ESPE: Universidad de las Fuerzas Armadas

Julio César Caicedo

ESPE: Universidad de las Fuerzas Armadas

Yesid Castro Aguilar

ESPE: Universidad de las Fuerzas Armadas

\section{Research Article}

Keywords: Physical Vapor Deposition PVD, Fatigue, AISI 1045 Steel, Carbo-nitrides and nitrides transition metals, TiCN, CrAIN, BCN

Posted Date: September 14th, 2021

DOI: https://doi.org/10.21203/rs.3.rs-866091/v1

License: (9) This work is licensed under a Creative Commons Attribution 4.0 International License. Read Full License 


\section{Abstract}

This current work evaluated the influence of Titanium Carbo-nitride (TiCN), Chromium Aluminum Nitride (CrAIN) and Boron Carbo-nitride (BCN) coatings deposited on AISI 1045 steel and its behavior in fatigue life. Suitable deposition parameters were established for the coatings to show high hardness onto the substrate, appropriate deposition time for polycrystalline growth and desired stoichiometry, as well as a stable layer thickness of $\sim 3 \mu \mathrm{m}$. The physical and chemical properties of the coatings obtained were established by X-ray diffraction (XRD), X-ray photo-electron spectroscopy (XPS) and nanoindentation; the scanning electron microscopy (SEM) was used for the analysis of the fracture surfaces of the samples subjected to fatigue. The analysis of the fatigue behavior of the uncoated and coated substrates were performed under rotary bending conditions applying maximum alternating stresses in the interval of 55$70 \%$ of the ultimate strength value, i.e. from 479 to $610 \mathrm{MPa}$, respectively; the test was performed at room temperature. The study of the results established that the fatigue resistance properties increased for the three types of coated samples, TiCN, BCN and CrAIN, with values of $9.6 \%, 4.2 \%$ and $3.9 \%$, respectively, calculated for $1 \times 10^{6}$ cycles. The highest value in fatigue life improvement corresponded to the TiCN coating, followed by BCN. This can be associated to the increase hardness present in the TiCN layer; this improved the mechanical properties of the coating. The examination of the fracture surfaces carried out in the tested samples (coated and uncoated), clearly demonstrate that the cracks produced by fatigue started in the surface of the coating and later propagated to the substrate. The mechanicals and fatigue results found in these ternary coatings deposited on AISI 1045 steel open a possibility of future applications in mechanical devices e.g. automotive applications that require high fatigue demands in service conditions.

\section{Introduction}

The physical vapor deposition (PVD) technique has been widely used in various industrial applications because the coatings improves the morphological, mechanical and tribological properties to various classes of substrates [1]. At present there is limited information on the variable load properties of machine elements with PVD coatings. The revision of the technical literature including the works and developments carried out in the last years in the obtaining and improvement of the physicochemical, mechanical and tribological properties of the PVD coatings, point out that the fatigue resistance of certain substrates will increase significantly with the addition of these coatings, due to an improvement in the fracture behavior for the material. This improvement in mechanical behavior is attributed to the added TiCN, TiN and others layers that prevents the propagation of cracks through the material [2-5]. An example of mechanical elements that must comply with solicitations to support variable loads and efforts are the components of an internal combustion engine, in particular the piston pin made of AISI 1045 steel, which is subjected to flexion fatigue, and the cubes (holes) in which it is lodged inside the engine must resist a surface pressure (pressure on the sliding surface) of $30 \mathrm{MN} / \mathrm{m}^{2}$ to $60 \mathrm{MN} / \mathrm{m}^{2}[6]$. Therefore, the new advanced surface treatments are progressively spreading in the production of industrial elements including those belonging to the automotive industry. The development of these new 
coatings simultaneously requires the study of other added properties such as fatigue resistance, to extend their application in certain operating conditions for a mechanical element. The improvement in the morphological and mechanical properties of the material will serve as a basis for its use in the manufacture of coatings for steels used in elements and parts of the automotive industry. Considering the above, TiCN, CrAIN and BCN coatings are expected to present better hardness, as well as other properties relevant to applications of elements subjected to high stress and severe wear $[5,7,8]$. Unfortunately, literature presents few researches focused on studying the fatigue resistance of TiCN, CrAIN and BCN coatings deposited on AISI 1045 steel. Although some authors [2, 5], E. S. Puchi-Cabrera [2] have studied the fatigue properties of steel substrates coated with TiCN layers, these studies do not relate the TiCN, CrAIN and BCN coating's performance in non-lubricated environments. Therefore, the aim of this work was to study the influence of carbo-nitrides and transition metal nitrides (TiCN, CrAIN and BCN) coatings deposited onto AISI 1045 steel under rotational fatigue behavior for protection synergies with potential applications for the metal-mechanic industry, which open a possibility of future applications in mechanical devices e.g. automotive applications that require high fatigue demands in service conditions.

\section{Material And Experimental Detail}

A multi-target sputtering magnetron was used for the deposition of the coatings, which facilitated the insitu deposition of both monolayers and multilayers. It has four (4) magnetrons (Torus - 4", $10 \mathrm{~cm}$ Kurt J. Lesker) with diametric dimensions of $10 \mathrm{~cm}$ each, three (3) radio frequency sources r. f. (13.56 MHz, RFX $600 \mathrm{~A}$ ) and three (3) direct current (MDX 500, Advanced Energy). The design of the equipment establishes the location of the magnetrons facing and equidistant from the central point, where the samples to be coated are fixed. It has a system for measuring and controlling the pressure (Baratron, MKS), a flow meter or gas flow controller with four (4) channels, the heating process is by temperature radiation with a maximum of $400^{\circ} \mathrm{C}$ (Athena 500) and it includes a rotational sample holder system and another planetary system for coating coin type and cylindrical type specimens, respectively (see Figs. 1a-b). The targets materials were 4 inches in diameter $(\sim 10 \mathrm{~cm}), 5 \mathrm{~mm}$ thick and $99.9 \%$ pure, silicon substrates with a crystallographic orientation (100) were used and machined AISI 1045 steel substrates (coin type, with $12.7 \mathrm{~mm}$ diameter and $5 \mathrm{~mm}$ thickness), the all substrates were subjected to a surface cleaning to remove organic contaminants for which an ultrasound system was used. The crystallographic structure determination of the TiCN, BCN and CrAIN coatings was analyzed by X-ray diffraction (PANalytical X 'pert proTM), using a Cu-Ka radiation source with a wavelength of $\lambda=1.5405 \AA$. For $X$-ray photo-electron spectroscopy (XPS) studies a SAGE HR100 (SPECSTM) equipment was used with a monochromatic source (Mg Ka $1253.6 \mathrm{eV}$ ), to determine the chemical composition of the coatings the CasaXPS V2.3.15 software was used. Mechanical characterization for all coatings was carried out with nano-indentation test by using a Ubi1-HysitronTM device, with a Berkovich diamond tip at variable loads. From the nanoindentation test, the load as a function displacement curves were obtained for the three coatings. Taking into account these curves, the hardness and elastic modulus were determined with the Oliver-Phar 
method [9]. For mechanical characterization of the AISI 1045 steel specimens, the ASTM $466-15$ Standard were employed [10] for fatigue tests.

To perform the fatigue test in rotary bending on the AISI 1045 steel substrates with TiCN, BCN, CrAIN coatings and on the uncoated steel substrate, it was necessary to perform tensile and hardness tests beforehand. The tension test in the AISI 1045 steel simples (Standard E8/E8M-13a) (see Fig. 2a) [11], was made to obtain properties such as the elastic modulus (E), yield strength (Sy), ultimate strength (Sut) and breaking strength (Srot). The data corresponding to yield strength and ultimate strength were used to determine the load regimes in the fatigue tests. One hundred and forty (140) samples were made for the rotary fatigue tests. Calibrated AISI 1045 steel bars of 5/8 inches in diameter and $6 \mathrm{~m}$ in length were used, to be later machined in a CNC lathe according to the dimensions specified in Standards ASTM 466 - 15 and ASTM E606/E606M - 12 (see Fig. 2b) [10, 12]. In the sanding process, sandpaper was used: $240,280,400$ and 600; then the samples were finally polished with diamond paste (range $2 \mu \mathrm{m}-4 \mu \mathrm{m}$, mesh size \#8000) to obtain the final finish. It was verified that the average roughness ( $R a=0.044 \mu \mathrm{m})$ was below $0.2 \mu \mathrm{m}$ giving compliance to the specifications of the standard used. Once the samples were prepared, they were coated with the three materials (TiCN, BCN and CrAIN). A calibration of the machine was made, comparing theoretical deformation values $\left(\varepsilon_{t}\right)$ with test deformation $\left(\varepsilon_{r}\right)$, having a maximum error of $5.6 \%$, which is acceptable. In this sense the AISI 1045 steel samples were made according to the dimensions specified in Standards ASTM 466 - 15 and ASTM E606/E606M - 12, due to that this geometrical form can simulate the steel pin, associate to the gudgeon pin. Therefore, in the Fig. $2 \mathrm{c}$ was simulated a mechanical condition where there was interaction of the assembly (metal-ceramic) associated with the coating and the metal surface of the hardened steel pin, as would happen, for example, in the gudgeon pin assembly inside the internal combustion engine (Automotive applications).

Fatigue failure, from $N=1$ to $N=1000$ cycles, is considered to be low cycle fatigue, while high cycle fatigue corresponds to failure in stress cycles greater than $10^{3}$ cycles. In addition, it was determined that the $\mathrm{S}-\mathrm{N}$ curve has ranges of finite and infinite life. In the transition range, which is the region between the finite and infinite life ranges, the fatigue resistance limit is determined, which is related to the number of technological cycles $(\mathrm{Ng})$, located somewhere between $10^{6}$ and $10^{7}$ cycles in the case of steels. This study was carried out with high cycle fatigue and the value of $\mathrm{Ng}=1 \times 10^{6}$ cycles was considered as the border between the finite and infinite life regions $[5,7,8,10,12-15]$. For the construction of the S-N curves of each material (AISI 1045, TiCN, BCN and CrAIN steel), five (5) samples were used for each level of stress, that is, approximately thirty (30) samples were tested for each type of curve obtained. For each level of stress an error percentage was established that did not exceed $15 \%$, using a $90 \%$ confidence level.

For this study the determination of the crystallographic structure of the TiCN, BCN and CrAIN coatings was performed using an X-ray diffractometer (PANalytical $\mathrm{X}^{\prime}$ pert pro ${ }^{\mathrm{TM}}$ ) with a Cu radiation source $\mathrm{Ka}$ and with a beam wavelength of $\lambda=1.5405 \AA$. The thickness of the coatings was verified using a KLA Tencor D-120 profilometer; the thickness of all the coatings was $3 \mu \mathrm{m}$. The analysis of the fracture surfaces was determined by scanning electron microscopy (SEM) with a JEOL Modelo JSM-6490LV'M (Phenom FEI) equipment. Fatigue tests were performed in a rotary bending machine HUNG TA Instrument Cia. Ltda., 
Model No./Serial No.: HT-8129/2031, which is designed to apply totally inverted stresses with a ratio of efforts $\mathrm{Re}=-1$. The tests were carried out at $3600 \mathrm{rpm}$, with a frequency of $60 \mathrm{~Hz}$. A diagram of the operating mechanism and main parts of the rotary bending equipment can be seen in Fig. 3 .

\section{Results And Discussion}

\subsection{X-Ray diffraction analysis}

Figures 4a-c present the diffraction patterns obtained for the TiCN, BCN and CrAIN coatings, which are the product of the analysis on the silicon substrates (100). The diffraction lines in the patterns show an order along the $2 \theta$ axis corresponding to a face centered cubic structure (FCC), $\mathrm{NaCl}$ type and space group Fm3m [16-17]. The substitution mechanism predominated in the formation of the three coatings, both for TiCN [18] and BCN; the carbon atoms $(C)$ substituted the nitrogen atoms $(N)$, which created a Tiordered, B-ordered and $\mathrm{C}-\mathrm{N}$ disordered system. For the CrAlN coating, the aluminum atoms (Al) were replaced by chromium atoms $(\mathrm{Cr})$, creating an ordered $\mathrm{Cr}$-Al system, while the nitrogen atoms $(\mathrm{N})$ were located in interstitial positions. In all three coatings the crystallization process formed a $\mathrm{NaCl}$ type FCC structure, the $\mathrm{Ti}, \mathrm{B}, \mathrm{Cr}$ and $\mathrm{Al}$ atoms were arranged in the Wyckoff $4 \mathrm{a}$ site, on the other hand the $\mathrm{C}$ and $\mathrm{N}$ atoms were arranged randomly in the Wyckoff $4 \mathrm{~b}$ site. The international indexing records JCPDF 00-0421488 and JCPDF 00-035-1293 for titanium and boron carbide nitride were taken as reference, while two indexings were made, taking the structure of chromium nitride (CrN) JCPDF 00-003-1157 and aluminum nitride (AIN) JCPDF 00-025-1495, for the coating of chromium aluminum nitride [18]. It is evident in Fig. 4c, that the ternary material CrAIN was the result of the combination of $\mathrm{CrN}$ and $\mathrm{AIN}$, which have the same $\mathrm{NaCl}$ type FCC crystalline structure and the space group 225- Fm3m. From the diffraction patterns of the TiCN and BCN coatings, high intensity peaks were obtained with orientation (111) belonging to the angles $2 \theta=36.342^{\circ}$ and $43.228^{\circ}$; on the other hand, a high intensity peak was obtained for CrAIN with orientation (200) belonging to the angle $2 \theta=41.646^{\circ}$. Jointly, small displacements were present in the peaks (111) and (200) towards smaller angles. The results obtained for the lattice parameters $\left(\mathrm{a}_{0}\right)$ in the TiCN, BCN and CrAlN coatings were the values $4.278 \AA, 3.622 \AA$ and $4.334 \AA$, respectively. We can establish from the analyzed results that the diffraction angles and lattice parameters were affected by the type of coating material.

\subsection{Chemical Composition of Coatings by Using XPS Analysis}

The Table 1 present the XPS results for all coatings, due to that the elemental signals spectra were obtained for the TiCN, BCN and CrAIN coatings, the signals for the coatings allow locating and defining the respective binding energies, which facilitate determining the chemical composition and stoichiometry of the ternary layers. For TiCN: Ti $(2 \mathrm{p} 3)=458.4, \mathrm{~N}(1 \mathrm{~s})=396.80, \mathrm{C}(1 \mathrm{~s})=284.8$ and Si $(2 \mathrm{p})=61.6$; for BCN: $\mathrm{N}(1 \mathrm{~s})=400, \mathrm{C}(1 \mathrm{~s})=285.6$ and $\mathrm{B}(1 \mathrm{~s})=192.8$; and for CrAlN: $\mathrm{Cr}(2 \mathrm{p})=475.99, \mathrm{~N}(1 \mathrm{~s})=396.97, \mathrm{Al}(2 \mathrm{~s})=$ 119 and $\mathrm{Al}(2 \mathrm{p})=74$. Therefore, the binding energy values of the coatings and XRD results (Fig. 4) 
confirm the formation of CrAIN ternary compound $[19,20]$. Finally, the stoichiometry was established for the three coatings $\left(\mathrm{Ti}_{32.45}-\mathrm{C}_{35.83}-\mathrm{N}_{31.72}, \mathrm{~B}_{48.63}-\mathrm{C}_{31.22}-\mathrm{N}_{20.15}\right.$ and $\left.\mathrm{Cr}_{40.27}-\mathrm{Al}_{38.01}-\mathrm{N}_{21.72}\right)$ [17].

Table 1

Atomic Percent of the chemical composition and stoichiometric relation for all TiCN, BCN and CrAIN coatings from XPS results.

\begin{tabular}{|c|c|c|c|c|c|c|c|c|c|}
\hline \multirow[t]{2}{*}{ Coatings } & \multicolumn{9}{|c|}{ Chemical elements } \\
\hline & C & $\mathbf{N}$ & $\mathrm{Ti}$ & B & $\mathrm{Cr}$ & Al & $\begin{array}{l}\mathrm{N} /(\mathrm{Ti}+ \\
\mathrm{C})\end{array}$ & $\begin{array}{l}N /(B+ \\
C)\end{array}$ & $\begin{array}{l}\mathrm{N} /(\mathrm{Al}+ \\
\mathrm{Cr})\end{array}$ \\
\hline TiCN & 35.83 & 31.72 & 32.45 & - & - & - & 0.46 & -- & - \\
\hline $\mathrm{BCN}$ & 31.22 & 20.15 & - & 48.63 & - & - & - & 0.25 & - \\
\hline CrAIN & - & 21.72 & - & - & 40.27 & 38.01 & - & - & 0.27 \\
\hline
\end{tabular}

\subsection{Coatings Mechanical Properties by Using Nanoindentation Test}

The Table 2 presents the mechanical properties for all coatings from nanoindentation results, in this Table 2 the coatings influence in the hardness and elastic modulus can be appreciated; it is also shown that the material with the lowest mechanical properties values was the TiCN $(\mathrm{H}=28 \mathrm{GPa}, \mathrm{E}=224 \mathrm{GPa})$, followed by $\operatorname{CrAIN}(\mathrm{H}=30 \mathrm{GPa}, \mathrm{E}=335 \mathrm{GPa})$ and then $\mathrm{BCN}(\mathrm{H}=33 \mathrm{GPa}, \mathrm{E}=251 \mathrm{GPa})$. Taking in account the last results, the elastic modulus $(E)$ is related to the type of material, but not to the material microstructure; in this sense the (E) depend on their crystal structure and its own lattice parameter [17]. Also, the hardness difference of the three coatings is due to the different crystallographic directions analyzed from XRD results Fig. 4, therefore the BCN coatings present highest hardness in relation to TiCN and CrAIN coatings.

Table 2

Presents the mechanical properties for all TiCN, BCN and CrAlN coatings from nanoindentation results.

\begin{tabular}{|lll|}
\hline Coatings & \multicolumn{2}{l|}{ Mechanical Properties } \\
\cline { 2 - 3 } & Hardness (GPa) & Elastic Modulus (GPa) \\
\hline BCN & 33 & 251 \\
\hline CrAIN & 30 & 335 \\
\hline TiCN & 28 & 224 \\
\hline
\end{tabular}

\subsection{Tension and Hardness Tests}


The material used as a substrate was AISI 1045 steel and the chemical composition in the state of supply is shown in Table 3. It was necessary to previously carry out the tensile test to determine certain mechanical properties of the substrate, this was fundamental for the planning of the test and the verification of the state of supply of the material. All tests were carried out at room temperature. Table 4 shows the results obtained in the tensile and Rockwell C (HRC and Vickers (HV) hardness tests. Three (3) samples were used, made of calibrated AISI 1045 steel (in supply state), obtaining a yield strength of Sy $=787.783 \mathrm{MPa}$ and a ultimate strength of Sut $=871.624 \mathrm{MPa}$. The Sy $/$ Sut $=0.904$ ratio of the material helped establish the stress relations applied in the fatigue test, which had to be less or equal to the established ratio. This ensured that the behavior of the material remained within the linear-elastic range while being subjected to the load levels used in fatigue.

Table 3

Chemical composition for calibrated AISI 1045 steel.

\begin{tabular}{|llllll|}
\hline Standard & $\%$ C & \%Mn & \%Si & \%P & \%S \\
\hline SAE 1045 & $0.43-0.50$ & $0.60-0.90$ & $0.15-0.25^{*}$ & 0.030 max. & 0.050 max. \\
\hline * SAE 1045 standard bars contain silicon as of 1 1/8". & \\
\hline
\end{tabular}

Table 4

Tensile and hardness test results for calibrated AISI 1045 steel.

\begin{tabular}{|c|c|c|c|c|c|c|}
\hline Samples & $\mathrm{E}(\mathrm{GPa})$ & $\begin{array}{l}\text { Sy } \\
(\mathrm{MPa})\end{array}$ & $\begin{array}{l}\text { Sut } \\
\text { (MPa) }\end{array}$ & $\begin{array}{l}\text { Srot } \\
\text { (MPa) }\end{array}$ & $\begin{array}{l}\text { Hardness } \\
\text { HRC }\end{array}$ & $\begin{array}{l}\text { Hardness } \\
\text { HV }\end{array}$ \\
\hline AISI 1045 & 204.563 & 787.783 & 871.624 & 717.045 & 21.913 & 403.375 \\
\hline $\begin{array}{l}\text { Standard } \\
\text { Deviation }\end{array}$ & $\stackrel{ \pm}{29.662}$ & \pm 13.625 & \pm 22.260 & \pm 10.691 & \pm 3.517 & \pm 21.725 \\
\hline
\end{tabular}

\subsection{Fatigue Tests}

For the fatigue test the stress-life method is used, this model is called the S-N curve or Wöhler diagrams $[2,13,21-22]$. The fatigue tests were performed on a HUNG TA Model No./Serial No.: HT-8129/2031 rotary bending machine, which applies loads that produce fully inverted sinusoidal stresses with a stress ratio of $\operatorname{Re}=-1$. An equivalent load analysis was done for the fatigue machine and this, along with the applied stress levels, were necessary to define the loads that were used. Eq. 1 comes from the equation of normal bending stress, also considering that the moment of inertia of the critical cross section was circular with a diameter $d s=6.35 \times 10^{-3} \mathrm{~m}$; this, together with the selected stress levels, was used to determine the weights applied in the test. The following relationships were chosen to determine the applied stress levels $70 \%, 65 \%, 60 \%$ and $55 \%$ of the ultimate strength value $[2,5,8,14,15,22]$. 
$\mathrm{S}=\frac{(\mathrm{M})(\mathrm{c})}{\mathrm{I}} \rightarrow \mathrm{S}=\frac{\left(\frac{\mathrm{Wa}}{2}\right)\left(\frac{\mathrm{ds}}{2}\right)}{\frac{\pi(\mathrm{d})^{4}}{\mathrm{~s}}} \rightarrow \mathrm{S}=\frac{16(\mathrm{Wa})}{\pi(\mathrm{ds})^{3}} \rightarrow \mathrm{W}=\frac{\pi(\mathrm{S})(\mathrm{ds})^{3}}{16 \mathrm{a}}$

Where $S=$ normal bending stress $\left(\mathrm{N} / \mathrm{m}^{2}\right), M=$ maximum bending moment $(\mathrm{Nm}), c=$ distance of the element furthest from the neutral axis $(\mathrm{m}), I=$ moment of inertia of the area with respect to the reference axis $\left(\mathrm{m}^{4}\right), W=$ applied weight $(\mathrm{N}), a=$ fixed distance $(0.2 \mathrm{~m})$ and $d s=$ diameter of the cross section $\left(6.35 \times 10^{-3} \mathrm{~m}\right)$.

Standards were established to carry out the fatigue test as follows: the tests were considered complete when the number of technological cycles $1 \times 10^{6}$ (for infinite life) was exceeded or when the failure of the material occurred before reaching that cycles number, $\mathrm{Ng}$ (for finite life). In addition, as a test validity criterion, it was determined that those in which the failure took place in the critical section of the sample would be accepted, otherwise would be discarded. ASTM 468 - 11 and ASTM 739 - 10 standards were used for the representation of the results [23-24]. The points on the graphs represent the data obtained experimentally and the continuous lines represent the trend adjustment lines; additionally, 95\% confidence bands are attached. Figure 5 shows the S-N curve of the uncoated material. With respect to the levels tested on the AISI 1045 steel for the transition range, the samples exceeded $1 \times 10^{6}$ cycles for stress levels of $50 \%$ and $45 \%$ of the ultimate strength value, which correspond to stresses of $435.81 \mathrm{MPa}$ and 392.23 MPa, respectively. These values obtained in the fatigue tests of the uncoated steel, as well as previous studies of substrates with coatings similar to the ones in this study, served as a reference for the determination of the stress levels applied in the transition range of the materials studied $[5,25]$.

Figure 6 shows the S-N curve for TiCN coated steel. An increase in fatigue resistance is observed when the graph is placed over the curve of the uncoated steel, which is consistent with previous studies conducted on metallic substrates with titanium carbo-nitride (TiCN) and titanium nitride (TiN) coatings [2, $5,8,22]$. For the TiCN-coated steel, the increase in the $1 \times 10^{6}$ cycles was $9.625 \%$. The transition range was located for stress levels of $47.5 \%$ and $45 \%$ of the ultimate strength value, corresponding to stresses of 414.02 MPa and 392.23 MPa, respectively.

The behavior of the BCN coated steel is shown in Fig. 7. Similar to the previous case, the graph is on top of the base curve (uncoated steel). Previous studies on various metallic substrates coated with tungsten nitride titanium (WTiN), tungsten titanium (WTi), tungsten nitride (WN) and zirconium nitride (ZrN) have shown an improvement in the fatigue behavior $[4,15]$. There was an increase in the $1 \times 10^{6}$ cycles of $4.215 \%$. The transition was established for stress levels of $45 \%$ and $40 \%$ of the ultimate strength value, corresponding to stresses of $392.23 \mathrm{MPa}$ and $348.65 \mathrm{MPa}$, respectively.

The data obtained in the fatigue tests for CrAIN-coated steel are detailed and represented in Fig. 8. Similar to the previous cases, the graph is located on top of the curve of the uncoated substrate; however, it presented the lowest improvement compared to the other two coatings (TiCN and BCN). The increase in fatigue resistance is lower to the obtained by $\mathrm{BCN}$, for the $1 \times 10^{6}$ cycles an improvement of $3.95 \%$ was 
obtained. The transition range was established at stress levels of $45 \%$ and $40 \%$ of the ultimate strength value, which corresponds to stresses of $392.23 \mathrm{MPa}$ and $348.65 \mathrm{MPa}$, respectively.

Finally, all the curves for the uncoated steel and with the three coatings ( $T i C N, B C N$ and $\mathrm{CrAIN}$ ) are shown in Fig. 9. For the three cases of the coated samples, an increase in fatigue resistance was found; this improvement in descending order corresponds to TiCN, BCN and CrAIN materials with $9.6 \%, 4.2 \%$ and $3.9 \%$, respectively. The highest gain in fatigue life corresponds to the TiCN coating, followed by $\mathrm{BCN}$; this can be explained by the presence of titanium in the material coating where titanium carbide (TiC) and nitrogen $(\mathrm{N})$ were used, as well as in the final singlelayer of TiCN; providing good adhesion in the coatings and the improvement in fatigue resistance. In this sense is possible to establish that the biaxial deformation in the planes was affected by the type of coating material. The values obtained determine the presence of tensile type stresses, being the lowest of them for the TiCN coating [17]. In the XRD analysis (Fig. 4) it was determined that these materials formed a NaCl type FCC structure; therefore, the Ti and $B$ atoms were located in the Wyckoff $4 a$ site, while the $C$ and $N$ atoms were randomly located in the Wyckoff $4 \mathrm{~b}$ site; the presence of titanium with a high atomic radius $(\mathrm{ra}=2 \AA)$ and boron with an intermediate atomic radius $(r a=1.17 \AA)$ in both structures, influenced that the mechanical properties (hardness and elastic modulus) (Table 2) affect the improvement of fatigue resistance. The increase of these mechanical properties together with the excellent adhesion of such coatings to the substrate, indirectly causes a delay in the nucleation process of fatigue cracks $[4,17,26]$. The above can be applied to the CrAIN coating, in which titanium is not present and has intermediate mechanical properties compared to the other coatings, which links to its low fatigue resistance.

Figure 10a, establishes the maximum alternating stress for the steels coated with TiCN, BCN, CrAIN and the uncoated steel, with values of $500.93 \mathrm{MPa}, 476.21 \mathrm{MPa}, 475.01 \mathrm{MPa}$ and $456.91 \mathrm{MPa}$, respectively. Figure 10b, shows the reported percentages of improvement in fatigue resistance for the three materials TiCN, BCN and CrAIN in comparison to the uncoated steel.

\subsection{Fractographic Analysis of Fracture Surfaces}

Selected fracture surfaces of the TiCN, BCN, and CrAIN coated and uncoated AISI 1045 steel, which were subjected to fatigue, were analyzed by scanning electron microscopy (SEM). The fractographic analysis of the sample surfaces only included higher maximum alternating stresses, that is, it was done at a stress level of $70 \%$ the ultimate strength value. The purpose of the study of these fracture surfaces was to allow the identification of crack nucleation sites [26], the appearance of coating delamination, to explain the fracture process of the substrate-coating systems and particularly to identify the way in which fatigue cracks propagate after nucleation.

Figures 11 a-c show the fracture surfaces for the TiCN coated substrate tested at high stress. Figure 11a shows the fracture surface of a coated sample subjected to a maximum alternating stress of 610.137 $\mathrm{MPa}$ and which failed at 45422 cycles. It can be stated that the failure of the specimen was the product of the simultaneous propagation of a series of cracks. Nucleation sites were located at the periphery of the surface, which led to the location of the fracture zone in the center of the fault surface. The presence 
of several fracture traces were examined, indicating the appearance of several nuclei at different sites along the contour of the sample. The results are consistent with information and studies reported in reference with similar deposition processes and types of coatings $[2,5,8,14,15,22]$. Figure $11 \mathrm{~b}$ shows detail in square $(A)$, where the starting site of one of the fatigue cracks is present. The direction of crack propagation is suggested by the white arrows on the fracture surface and the direction of the arrows determine the subsequent expansion of the cracks. In this case, it can be observed that the core that originates the fatigue crack appeared at the periphery of the sample and not in the substrate, at the interface between coating and substrate. The detailed view of the area represented in square (B) is seen in Fig. 11c, which reveals the fracture of the sample at this crack initiation site.

Figures 12a-c show the fracture surfaces for the BCN coated steel tested at high stress. Figure 12a, defines the failure surface of a sample tested at $610.137 \mathrm{MPa}$ and which failed at 28428 cycles. Image analysis indicates that the sample failure was established by a crack protruding from the surface contour, the fracture occurred as a product of the propagation of the A-nucleated crack, and this led to the fracture zone being located at the opposite end of the sample. Other adjacent cracks are observed on the fracture surface. Similar failure processes as described above with different coatings are consistent with other results obtained $[4,15,27]$. The magnified view of the area identified in square $(A)$ is shown in Fig. 12b, here the direction of propagation of the cracks can be clearly established. An additional magnified view of the crack initiation site is shown in Fig. 12c, which also illustrates the partial delamination of the coating at the site where the crack was probably nucleated in square (B).

The fracture surfaces for the last highly stressed CrAlN coating substrate are shown in Figs. 13a-c. Figure 13a determines the fracture surface of a coated specimen tested with a maximum alternating stress of 610.137 MPa and which failed at 10482 cycles. Image analysis corroborates that the sample fracture was the result of multiple propagations of a series of cracks, which nucleated at the sample contour and guided the fracture zone to the center of the surface. The presence of several traces of cracks indicates that they nucleated at different sites on the periphery of the fault surface. These surface results are consistent with similar coating studies $[15,27]$. The area in detail in square (A) determines one of the probable starting points of one of the cracks, shown in Fig. 13b. The white arrows in the section of the fracture suggest the direction of expansion and the direction of the arrows establish the growth of the crack. It can also be stated that the crack nucleated at the edge of the section and not in the substrate, near the substrate-coating interface. Figure $13 \mathrm{c}$ is an enlargement of the area represented in square (B), it shows the final fracture of the specimen at the starting site of the analyzed crack.

Finally, for comparison purposes, Figs. 14a-c show the fracture surfaces of an uncoated AISI 1045 steel, tested at high stress. Figure 14a shows the surface of an uncoated specimen tested at $610.137 \mathrm{MPa}$ and which failed at 11312 cycles. It was determined that the sample fracture is a product of the propagation of a single crack instead of multiple cracks initiated at the periphery. The surface did not have a flat appearance typical in fatigue, showing irregularity in the entire section analyzed. The fracture zone was located at the opposite end from the beginning of crack formation at A. Figure 14b, shows an enlargement of the A area, where the direction of crack propagation is defined by the white arrows. An

Page $10 / 28$ 
enlargement of the crack nucleation start site is shown in Fig. 14c, where the final fracture of the substrate was verified. The results obtained are consistent with references consulted $[7,13]$.

The results obtained on the fracture surfaces obey the established theory, fractures have their beginning in material discontinuities where the cyclic stress is maximum. The fracture surfaces are flat and perpendicular to the stress axis, and they follow the determined theoretical sequence: stage $I$ is the beginning of one or more microcracks; in stage II the microcracks form parallel surfaces in the shape of plateaus, known as beach marks; and stage III consists of sudden and fast fracture. Fatigue studies using surface treatment, such as plasma nitriding, establish the same sequence for the fracture; however, they have higher increases in fatigue strength limit (23.76\%) [26]. It is necessary to mention that processes of thermal spray coating HP/HVOF of tungsten carbide and hard chrome plating, have adverse effects on the fatigue resistance of steels [28].

\subsection{Correlation Between Mechanical and Fatigue Properties}

Figure 15a shows the relationship between coating nature, hardness and fatigue resistance for all coatings deposited on the industrial steel substrates. It is clearly shown that the improvement in hardness $(\mathrm{H})$, elastic modulus (E) (Table 2), the increase of the maximum alternating tension (Sa) as a functions of cycles number (Fig. 10a) and the increase of fatigue resistance (Fig. 10b), have incidence when the coatings nature (material's type) were changes. From this correlation it is possible to determine that one merit index [29] associates the increment coatings hardness and the increase of fatigue resistance (\%) at the same coating type. Therefore, the TiCN coating offers the best synergy for mechanical and fatigue properties with good hardness and a high maximum alternating tension (Sa) which is very important for mechanical applications in the devices e.g. automotive applications that require high fatigue demands in service conditions. We can establish from the Fig. $15 \mathrm{~b}$ results, that the biaxial deformation in the plane is affected by the coating material type, the values obtained determine the presence of tensile-type stresses in the following order: $\varepsilon=-3.1794 \times 10^{-3}$ for TiCN, $\varepsilon=-0.0110$ for BCN and $\varepsilon=-0.0447$ for CrAIN. The TiCN coating has the lowest tensile stress value.

\section{Conclusions}

The TiCN, BCN and CrAIN coatings were satisfactorily deposited on AISI 1045 steel substrates. So from the diffraction analysis (XRD), chemical results (XPS) and nanoindentation test was possible to establish crystalline structure, stoichiometric relation are related to the improvement in the mechanical properties (hardness and elastic modulus) as well as to the adhesion of the coatings. In this sense the increase in mechanical properties together with the excellent adhesion of the coatings ( $\mathrm{TiCN}, \mathrm{BCN}$ and $\mathrm{CrAIN}$ ) to the substrate, indirectly causes a delay in the nucleation process of fatigue cracks, thus improving fatigue resistance. 
The fatigue resistance property increased for tests with coated samples, the material with the greatest improvement was TiCN with $9.63 \%$, followed by BCN with $4.22 \%$ and finally CrAIN with $3.95 \%$, calculated for $N=1 \times 10^{6}$ cycles. The highest values of fatigue life corresponded to TiCN material. This could be justified by the presence of titanium in the crystal structure where titanium carbide (TiC) and nitrogen (N) were used, providing the best mechanical properties and a good adhesion in the coatings. As well as the lower presence of tensile type stresses for the TiCN coating.

The study of the fracture surfaces carried out on the steels tested (both coated and uncoated), clearly establishes that the nucleation sites were on the periphery of the surface. These originated the growth of the crack and led to the location of the fracture zone at the opposite end to the formation of the nucleus.

Finally the study of mechanicals properties and fatigue resistance in the TiCN, BCN and CrAIN coatings simultaneously where was evidenced the improvement mechanical properties and the maximum alternating tension (Sa) open their application in high dynamic loads on substrates used in the mechanicals elements and parts of the automotive industry.

\section{Declarations}

\section{a. Funding. (Not applicable) \\ b. Conflicts of interest/Competing interests}

The authors declare that they have no conflicts of interest with any other author, company, institution for intellectual property or financing of the current research.

Juan Francisco Correa

Juan Franc
Jácome

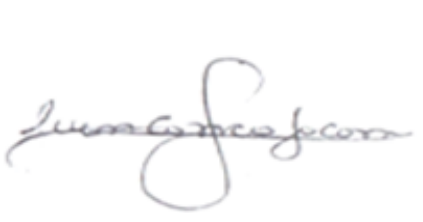

Julio César Caicedo

Angulo

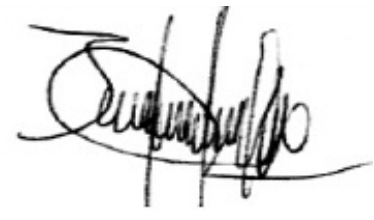

Yesid Aguilar Castro

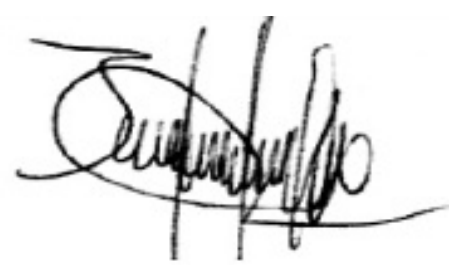

\section{c. Availability of data and material (data transparency). (Not applicable)}

d. Code availability (software application or custom code). (Not applicable) 


\section{e. Authors' contributions}

This current work evaluated the influence of Titanium Carbo-nitride (TiCN), Chromium Aluminum Nitride (CrAIN) and Boron Carbo-nitride (BCN) coatings deposited on AISI 1045 steel and its behavior in fatigue life. The mechanicals and fatigue results found in these ternary coatings deposited on AISI 1045 steel open a possibility of future applications in mechanical devices e.g. automotive applications that require high fatigue demands in service conditions.

\section{f. Ethics approval}

Our declaration which include that:

1. Our article is original.

2. Our article has been written by the stated authors who are ALL aware of its content and approve its submission.

3. Our article has not been published previously

4. Our article is not under consideration for publication elsewhere

5. No conflict of interest exists.

6. If accepted, our article will not be published elsewhere in the same form, in any language, without the written consent of the publisher.

\section{g. Consent to participate}

The authors declare that they have no known competing financial interests or personal relationships that could have appeared to influence the work reported in this paper.

\section{h. Consent for publication}

Our paper describes phenomenon that occurs in different materials e.g. steel and Coatings, moreover our paper present some novel and innovative TiCN, CrAIN and BCN Coatings that offers the improve on surface properties and response to surface physicals perturbations, specifically the analysis of the fatigue behavior of the uncoated and coated substrates.

Due to the above, we ask that you consider your decision to take the opportunity to publish our manuscript in this important magazine.

\section{References}


1. J. C. Caicedo et al., (2010) "TiCN/TiNbCN multilayer coatings with enhanced mechanical properties," Appl. Surf. Sci., vol. 256, no. 20, pp. 5898-5904. https://doi.org/10.1016/j.apsusc.2010.03.071

2. E. S. Puchi-Cabrera, M. H. Staia, D. T. Quinto, C. Villalobos-Gutiérrez, and E. Ochoa-Pérez, (2007) "Fatigue properties of a SAE 4340 steel coated with TiCN by PAPVD," Int. J. Fatigue, vol. 29, no. 3, pp. 471-480. https://doi.org/10.1016/j.ijfatigue.2006.05.003

3. H. Singh, G. Ramirez, O. Eryilmaz, A. Greco, G. Doll, and A. Erdemir, (2016) "Fatigue resistant carbon coatings for rolling/sliding contacts," Tribol. Int., vol. 98, no. 2, pp. 172-178. https://doi.org/10.1016/j.triboint.2016.02.008

4. J. A. M. Ferreira, J. D. M. Costa, and V. Lapa, (1997) "Fatigue behaviour of 42Cr Mo4 steel with PVD coatings," Int. J. Fatigue, vol. 19, no. 4, pp. 293-299. https://doi.org/10.1016/S0142-1123(97)000078

5. Y. L. Su, S. H. Yao, C. S. Wei, W. H. Kao, and C. T. Wu, (1999) "Influence of single- and multilayer TiN films on the axial tension and fatigue performance of AISI 1045 steel," Thin Solid Films, vol. 338, no. 1-2, pp. 177-184. https://doi.org/10.1016/S0040-6090(98)00880-3

6. H. Gerschler et al., (1985) Tecnología del automóvil Tomo 2, Primera ed. EDITORIAL REVERTÉ, S. A. Barcelona.

7. M. Marín O., A. Porrello, C. Alfonzo, and S. Cabello-Sequera, (2014) “Determinación de la curva S-N-P a través del método Maennig para el acero AISI 1045 sometido a un tratamiento térmico de normalizado," Rev. Ing. UC, vol. 21, no. 3, pp. 38-44.

8. J. A. Berríos, D. G. Teer, and E. S. Puchi-Cabrera, (2001) "Fatigue properties of a 316L stainless steel coated with different TiNx deposits," Surf. Coatings Technol., vol. 148, no. 2-3, pp. 179-190. https://doi.org/10.1016/S0257-8972(01)01346-9

9. W. C. Oliver and G. M. Pharr, (1992) "An improved technique for determining hardness and elastic modulus using load and displacement sensing indentation experiments," J. Mater. Res., vol. 7, no. 6, pp. 1564-1583. https://doi.org/10.1557/JMR.1992.1564

10. ASTM E466-15, (2017) Standard Practice for Conducting Force Controlled Constant Amplitude Axial Fatigue Tests of Metallic Materials. United States, pp. 1-6.

11. ASTM E8/E8M-13a, (2010) Standard Test Methods for Tension Testing of Metallic Materials. United States, pp. 1-27.

12. ASTM E606/E606M-12, (2013) Standard Test Method for Strain-Controlled Fatigue Testing, vol. 92. United States, pp. 1-16.

13. C. Polanco P. and J. Peña E., (2011) “Ensayo de Fatiga en Flexión Rotativa del Acero AISI-SAE 1018 por el Método Esfuerzo-Vida," Dsp. ESPOL, vol. 1, pp. 1-8.

14. E. S. Puchi-Cabrera et al., (2010) "Fatigue behavior of a 316 stainless steel coated with a DLC film deposited by PVD magnetron sputter ion plating," Mater. Sci. Eng. A, vol. 527, no. 3, pp. 498-508. https://doi.org/10.1016/j.msea.2009.09.030

15. J. A. Berríos-Ortíz, J. G. La Barbera-Sosa, D. G. Teer, and E. S. Puchi-Cabrera, (2004) “Fatigue properties of a 316L stainless steel coated with different ZrN deposits," Surf. Coatings Technol., vol. 
179, no. 2-3, pp. 145-157, https://doi.org/10.1016/S0257-8972(03)00808-9

16. P. E. Hovsepian, A. P. Ehiasarian, and I. Petrov, (2014) "Structure evolution and properties of TiAICN/VCN coatings deposited by reactive HIPIMS," Surf. Coatings Technol., vol. 257, pp. 38-47. https://doi.org/10.1016/j.surfcoat.2014.07.065

17. J. F. Correa, W. Aperador, J. C. Caicedo, N. C. Alba, and C. Amaya, (2020) "Structural, mechanical and tribological behavior of TiCN, CrAIN and BCN coatings in lubricated and non-lubricated environments in manufactured devices," Mater. Chem. Phys., vol. 252, pp. 1-27. https://doi.org/10.1016/j.matchemphys.2020.123164

18. J. C. Caicedo, W. Aperador, M. Mozafari, and L. Tirado, (2018) "Evidence of Electrochemical Resistance on Ternary V-C-N Layers," Silicon, vol. 10, no. 6, pp. 2499-2507. https://doi.org/10.1007/s12633-018-9782-7

19. A. Vyas, K. Y. Li, Z. F. Zhou, and Y. G. Shen, (2005) "Synthesis and characterization of CNx/TiN multilayers on Si (100) substrates," Surf. Coatings Technol., vol. 200, no. 7, pp. 2293-2300. https://doi.org/10.1016/j.surfcoat.2004.10.015

20. J. E. Nocua, G. Morell, F. Piazza, and B. R. Weiner, (2012) "Síntesis y caracterización de nanoestructuras estequiométricas de nitruro de boro," Superf. y vacío, vol. 25, no. 3, pp. 194-198.

21. R. G. Budymas and J. K. Nisbett, (2008) Diseño en ingeniería mecánica de Shigley, Octava edi. México, D. F..

22. E. S. Puchi-Cabrera, F. Matínez, I. Herrera, J. A. Berríos, S. Dixit, and D. Bhat, (2004) “On the fatigue behavior of an AISI 316L stainless steel coated with a PVD TiN deposit," Surf. Coatings Technol., vol. 182, no. 2-3, pp. 276-286. https://doi.org/10.1016/j.surfcoat.2003.07.003

23. ASTM E468-11, (2011) Standard Practice for Presentation of Constant Amplitude Fatigue Test Results for Metallic Materials. Unites States, pp. 1-6.

24. ASTM E739-10, (2017) Standard Practice for Statistical Analysis of Linear or Linearized Stress-Life $(S-N)$ and Strain-Life $(\varepsilon-N)$ Fatigue Data. United States, pp. 1-7.

25. E. S. Puchi-Cabrera et al., (2010) "Fatigue behavior of a SAE 1045 steel coated with Colmonoy 88 alloy deposited by HVOF thermal spray," Surf. Coatings Technol., vol. 205, no. 4, pp. 1119-1126. https://doi.org/10.1016/j.surfcoat.2010.01.011

26. L. B. Winck, J. L. A. Ferreira, J. A. Araujo, M. D. Manfrinato, and C. R. M. Da Silva, (2013) "Surface nitriding influence on the fatigue life behavior of ASTM A743 steel type CA6NM," Surf. Coatings Technol., vol. 232, pp. 844-850. https://doi.org/10.1016/j.surfcoat.2013.06.110

27. E. S. Puchi-Cabrera et al., (2008) "Fatigue behavior of AA7075-T6 aluminum alloy coated with ZrN by PVD," Int. J. Fatigue, vol. 30, no. 7, pp. 1220-1230. https://doi.org/10.1016/j.jfatigue.2007.09.001

28. M. P. Nascimento, R. C. Souza, I. M. Miguel, W. L. Pigatin, and H. J. C. Voorwald, (2001) "Effects of tungsten carbide thermal spray coating by HP/HVOF and hard chromium electroplating on AISI 4340 high strength steel," Surf. Coatings Technol., vol. 138, no. 2-3, pp. 113-124. https://doi.org/10.1016/S0257-8972(00)01148-8 
29. J. C. Caicedo, L. Yate, G. Cabrera, W. Aperador, G. Zambrano, and P. Prieto, (2011) "Effect of negative bias voltage on mechanical and electrochemical nature in Ti-W-N coatings," J. Mater. Sci., vol. 46, pp. 1244-1252. https://doi.org/10.1007/s10853-010-4904-7

\section{Figures}

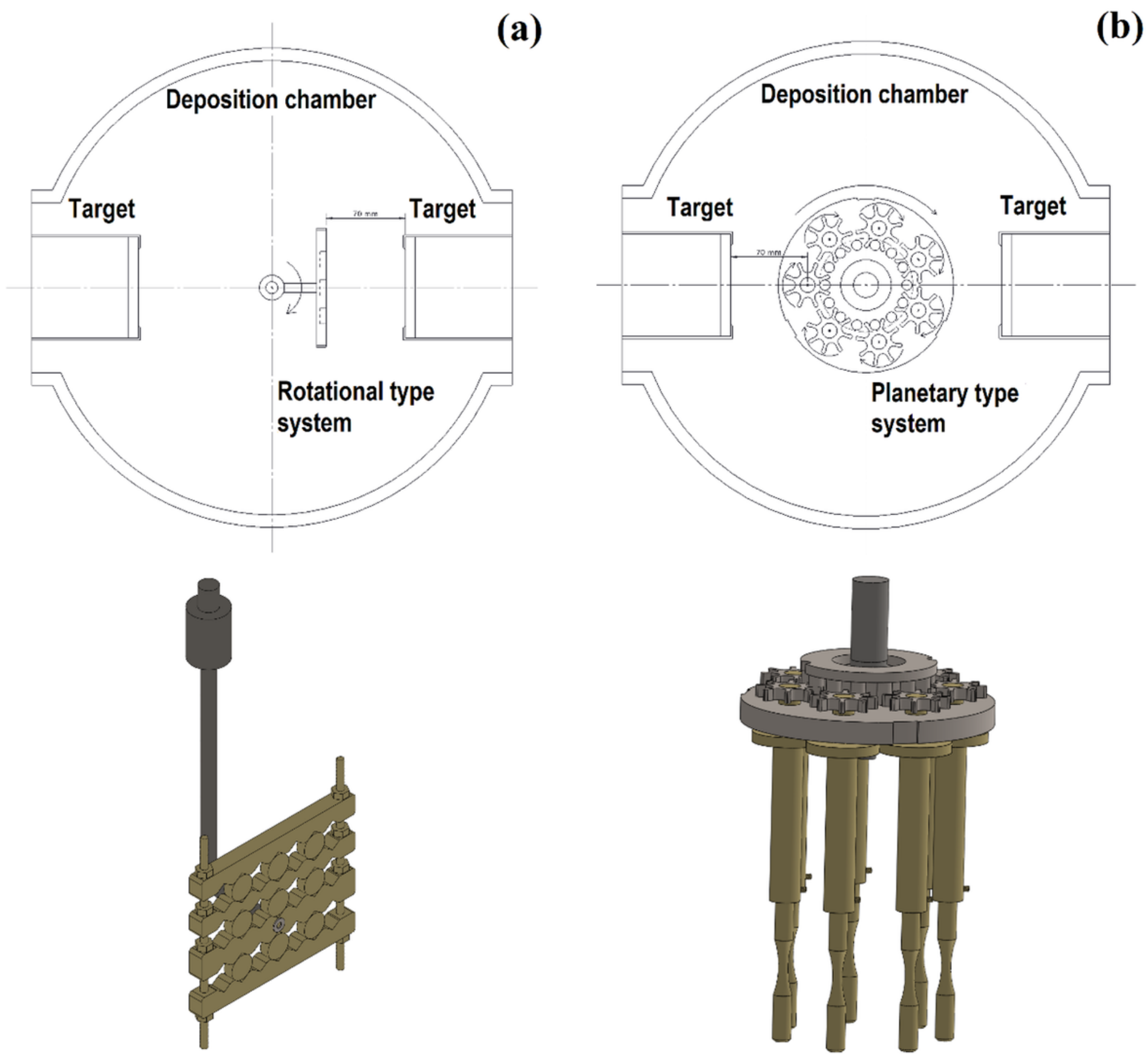

Figure 1

Sample-holder systems (a) rotational type, (b) planetary type. 


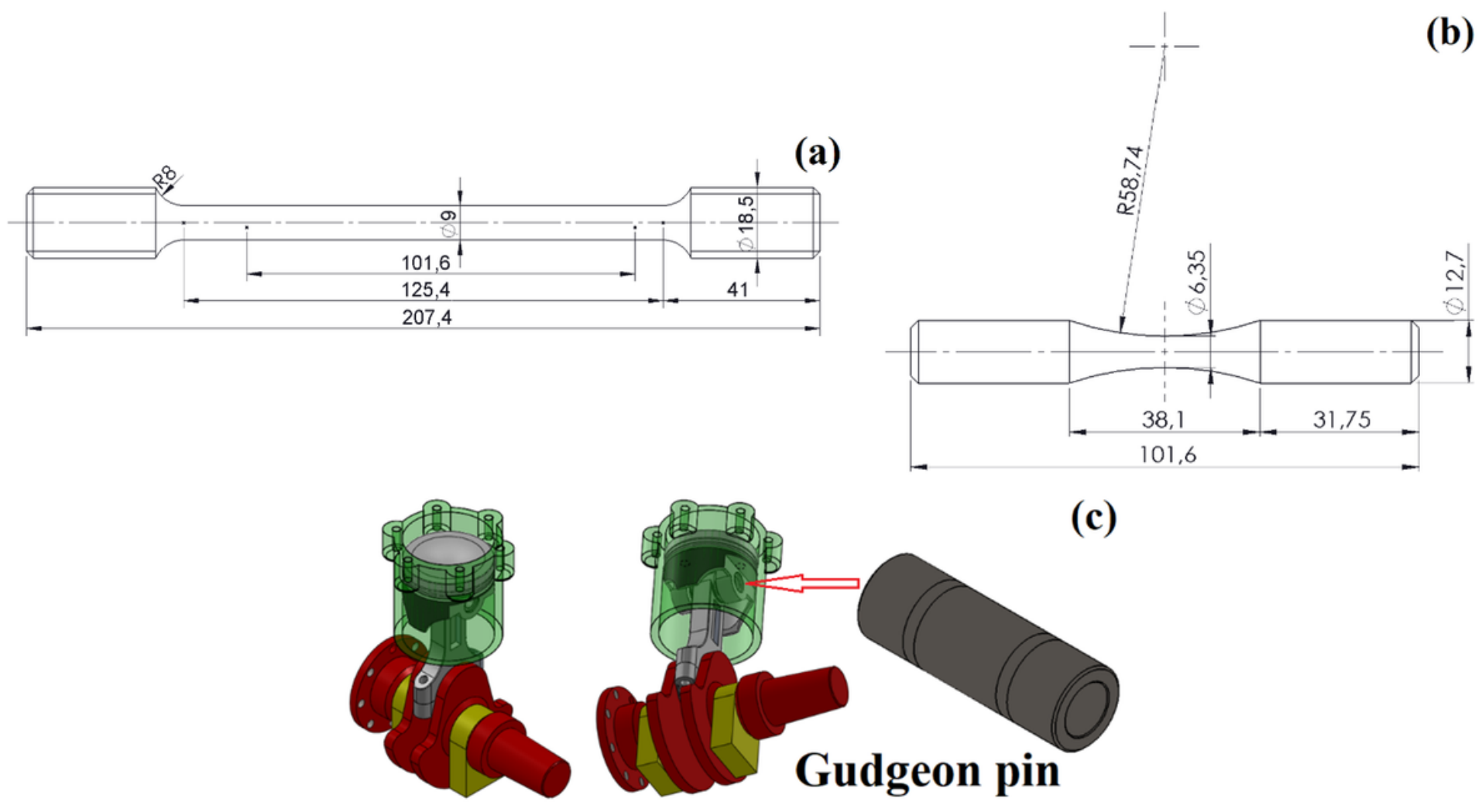

Figure 2

Standard dimensions for: (a) tensile specimen (Standard ASTM E8/E8M- 13a), (b) fatigue specimen (Standards ASTM 466-15 and ASTM E606/E606M-12) and (c) location of the gudgeon pin inside the engine.

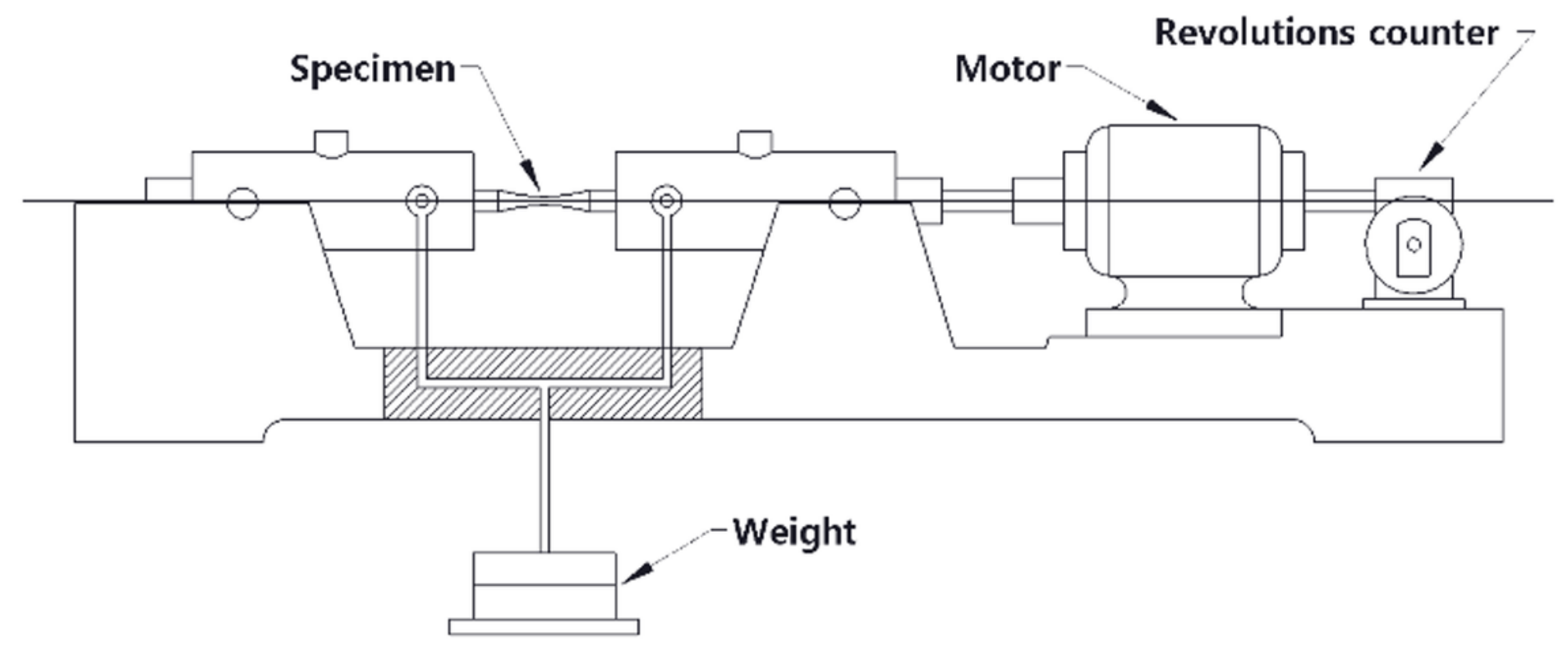

Figure 3

Mechanism and main parts of the rotary fatigue testing equipment. 

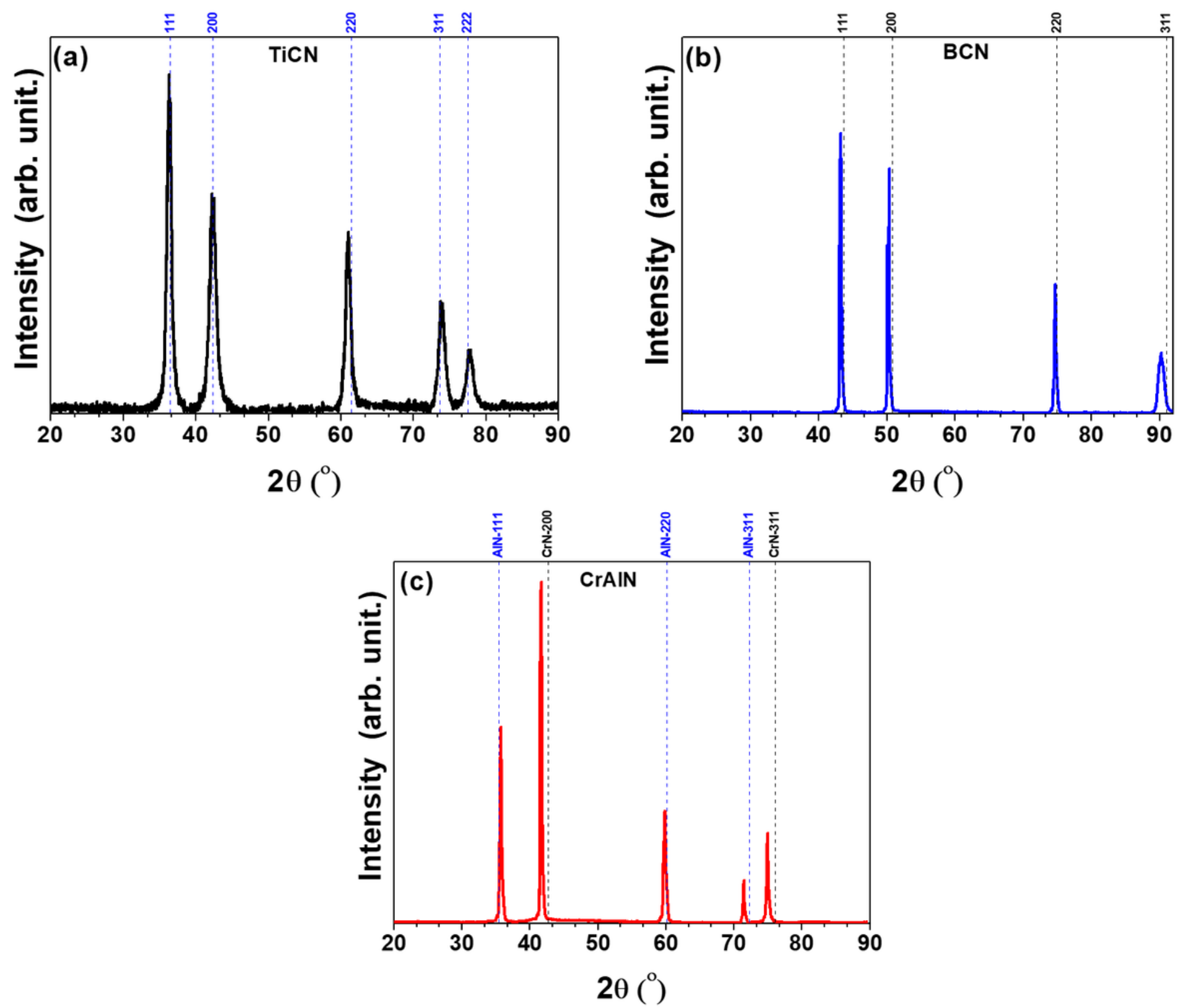

Figure 4

Diffraction patterns for all coatings (a) TiCN, (b) BCN and (c) CrAIN. The dotted lines indicate the position of the peaks obtained from the international indexing files (JCPDF) of TiCN, BCN and CrN-AIN, respectively. 


\begin{tabular}{|c|c|}
\hline Stress, (Sa) & Cycles, (N) \\
\hline 610.137 & 2834 \\
\hline 610.137 & 11312 \\
\hline 610.137 & 7417 \\
\hline 610.137 & 4229 \\
\hline 566.556 & 71441 \\
\hline 566.556 & 45282 \\
\hline 566.556 & 78012 \\
\hline 522.974 & 141147 \\
\hline 522.974 & 126265 \\
\hline 479.393 & 149490 \\
\hline 479.393 & 149960 \\
\hline 479.393 & 89921 \\
\hline 479.393 & 318386 \\
\hline 479.393 & 106689 \\
\hline 435.812 & 1473256 \\
\hline 435.812 & 1658890 \\
\hline 435.812 & $200000 *^{*}$ \\
\hline 392.231 & $200000 *^{*}$ \\
\hline 392.231 & $200000 *^{*}$ \\
\hline 392.231 & $200000 *^{*}$ \\
\hline$*$ Transition range (run out) \\
\hline
\end{tabular}

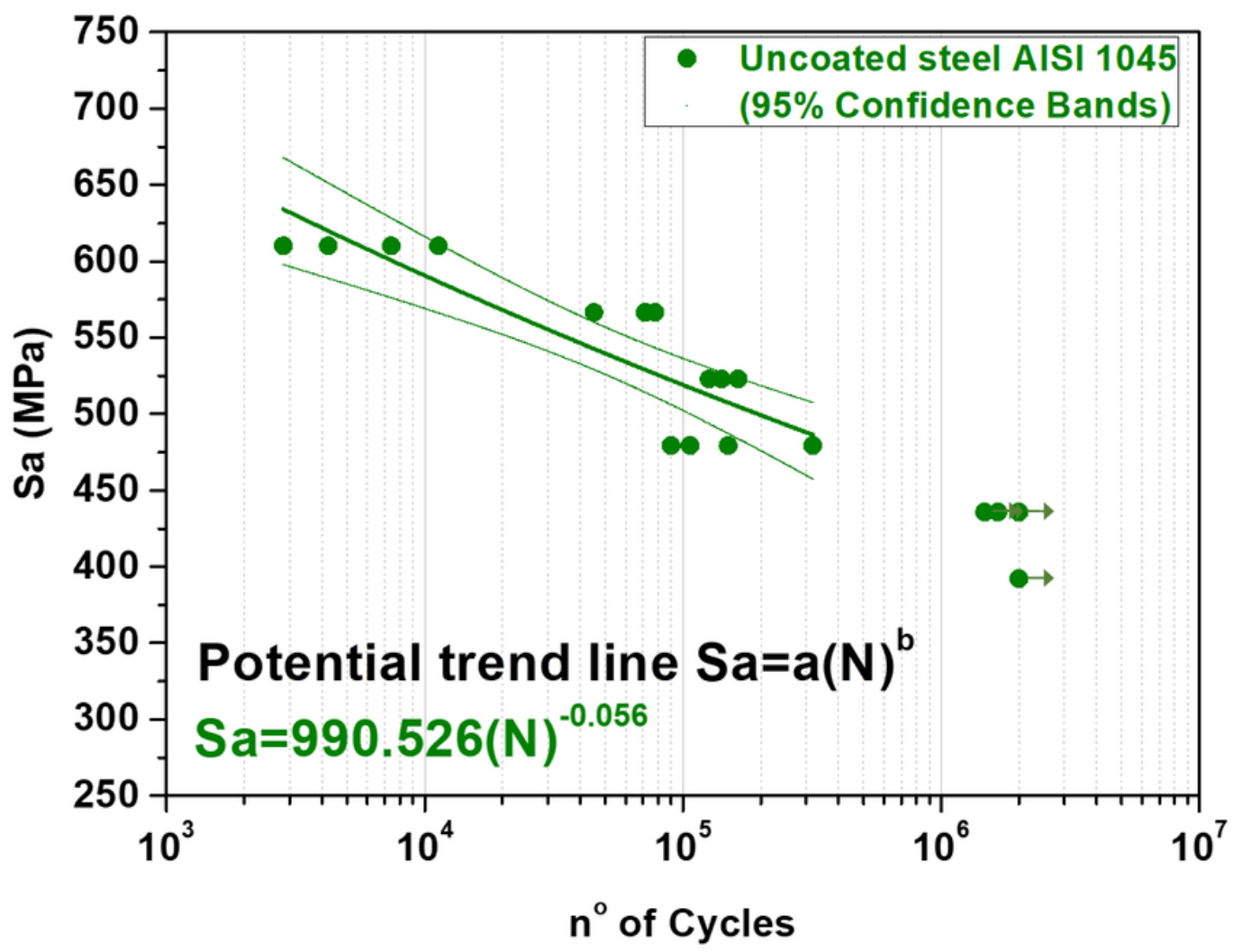

Figure 5

Maximum alternating tension (Sa) as a function of the number of failure cycles $(\mathrm{N})$ for uncoated steel.

\begin{tabular}{|c|c|}
\hline Stress, (Sa) & Cycles, (N) \\
\hline 610.137 & 45422 \\
\hline 610.137 & 47424 \\
\hline 610.137 & 2041 \\
\hline 610.137 & 184728 \\
\hline 566.556 & 12717 \\
\hline 566.556 & 96498 \\
\hline 566.556 & 88370 \\
\hline 522.974 & 56800 \\
\hline 522.974 & 417506 \\
\hline 522.974 & 446780 \\
\hline 479.393 & 95587 \\
\hline 479.393 & 154316 \\
\hline 479.393 & 219271 \\
\hline 479.393 & 510838 \\
\hline 479.393 & 490223 \\
\hline 435.812 & 488361 \\
\hline 435.812 & 232677 \\
\hline 435.812 & $2000000 *$ \\
\hline 392.231 & 649726 \\
\hline 392.231 & $2000000 *$ \\
\hline 392.231 & $2000000 *$ \\
\hline
\end{tabular}

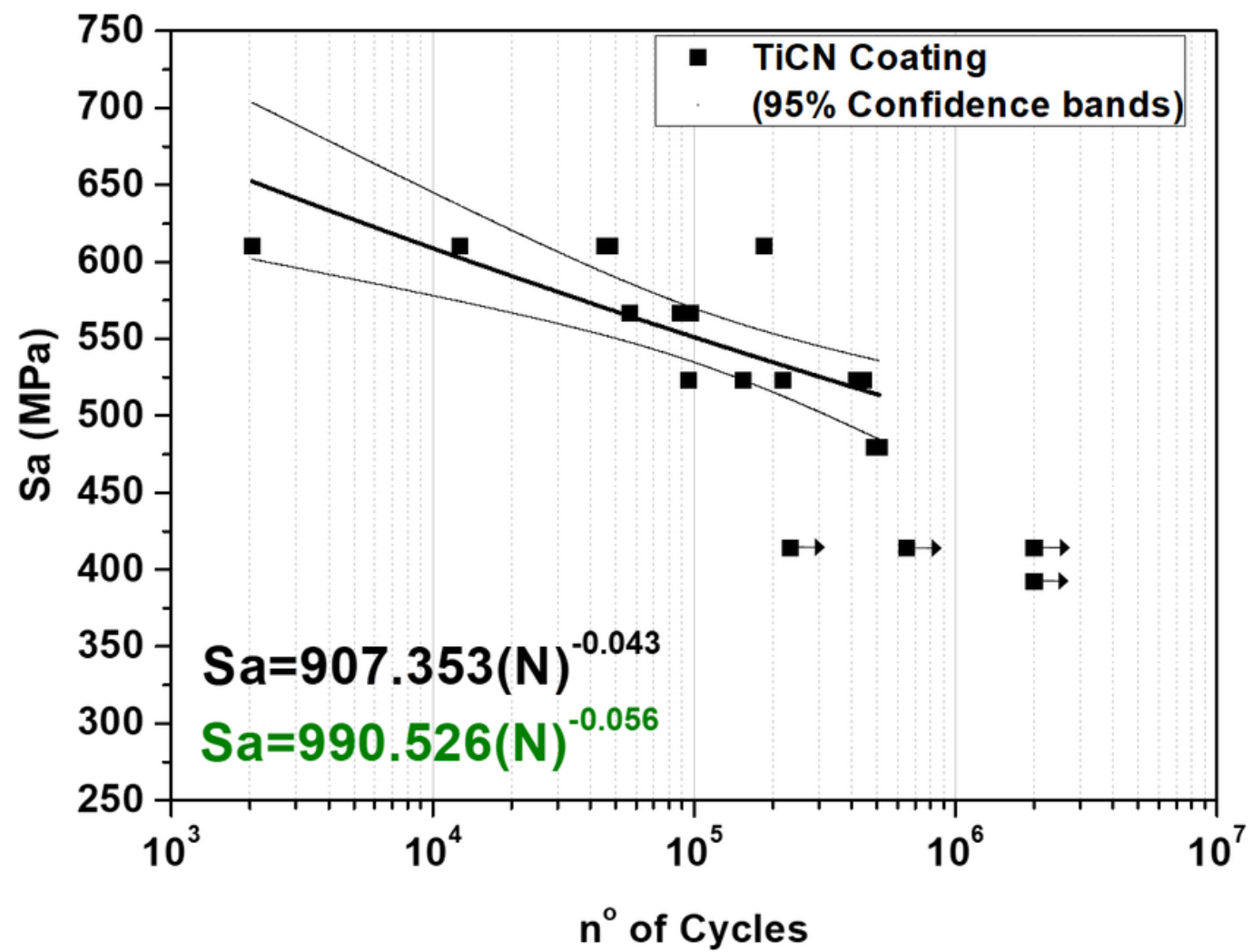

Figure 6 
Maximum alternating tension ( $\mathrm{Sa}$ ) as a function of the number of failure cycles $(\mathrm{N})$ for the TiCN-coated steel.

\begin{tabular}{|c|c|}
\hline Stress, (Sa) & Cycles, (N) \\
\hline 610.137 & 28428 \\
\hline 610.137 & 32401 \\
\hline 610.137 & 28022 \\
\hline 610.137 & 4285 \\
\hline 610.137 & 25456 \\
\hline 566.556 & 73211 \\
\hline 566.556 & 24898 \\
\hline 566.556 & 15496 \\
\hline 566.556 & 9554 \\
\hline 522.974 & 202443 \\
\hline 522.974 & 211916 \\
\hline 522.974 & 169099 \\
\hline 479.393 & 462383 \\
\hline 479.393 & 468351 \\
\hline 479.393 & 314744 \\
\hline 392.231 & 259902 \\
\hline 392.231 & $2000000^{*}$ \\
\hline 348.650 & $2000000^{*}$ \\
\hline 348.650 & $2000000^{*}$ \\
\hline$*$ Transition range (run out) \\
\hline
\end{tabular}

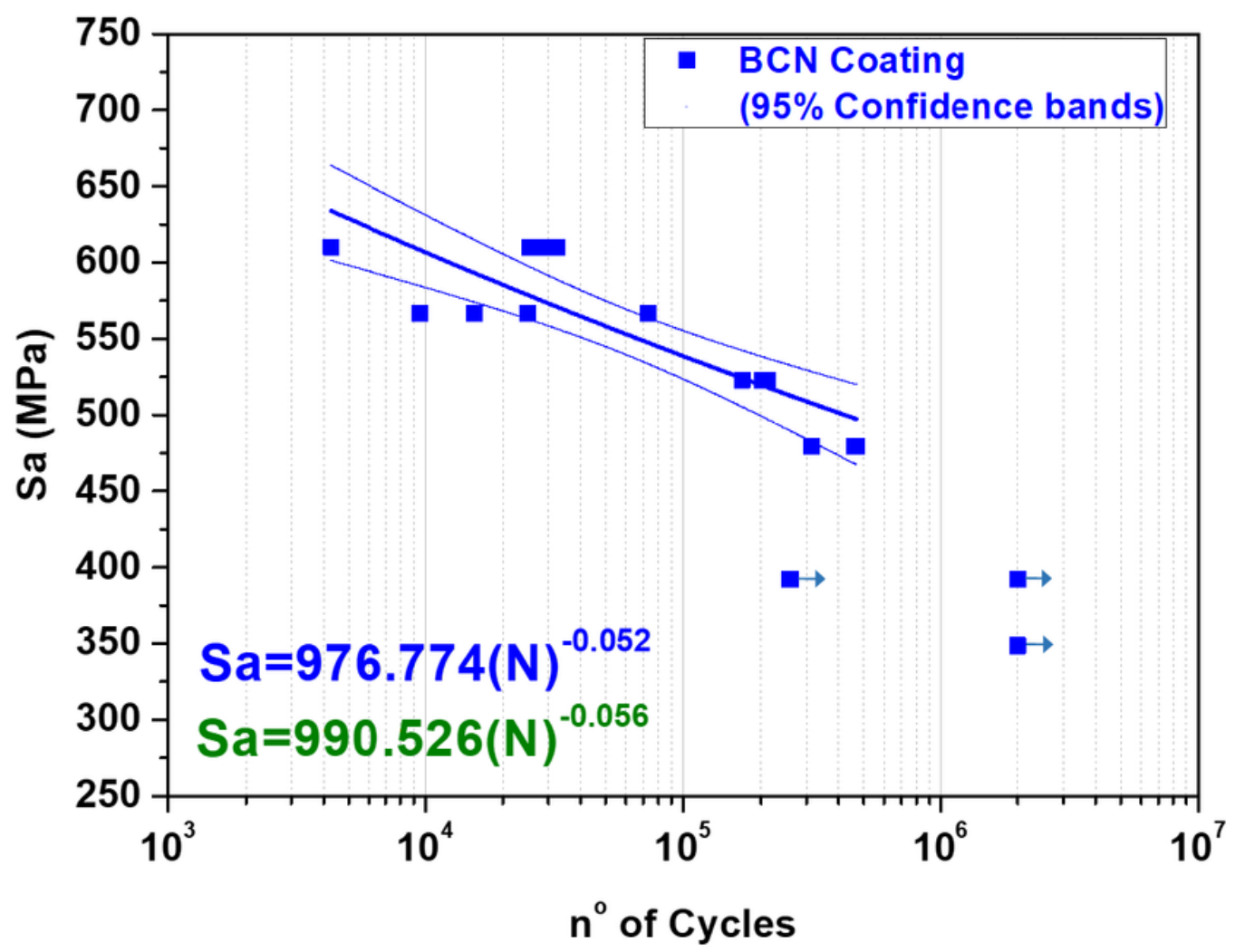

Figure 7

Maximum alternating tension (Sa) as a function of the number of failure cycles $(\mathrm{N})$ for the $\mathrm{BCN}$-coated steel. 


\begin{tabular}{|c|c|}
\hline Stress, (Sa) & Cycles, (N) \\
\hline 610.137 & 10482 \\
\hline 610.137 & 5485 \\
\hline 610.137 & 15627 \\
\hline 610.137 & 5666 \\
\hline 566.556 & 102032 \\
\hline 566.556 & 106382 \\
\hline 566.556 & 94351 \\
\hline 566.556 & 80632 \\
\hline 522.974 & 195512 \\
\hline 522.974 & 219040 \\
\hline 522.974 & 222806 \\
\hline 522.974 & 220803 \\
\hline 479.393 & 252731 \\
\hline 479.393 & 239539 \\
\hline 479.393 & 257283 \\
\hline 392.231 & 255746 \\
\hline 392.231 & 291355 \\
\hline 392.231 & $2000000^{*}$ \\
\hline 348.650 & $2000000^{*}$ \\
\hline 348.650 & $2000000^{*}$ \\
\hline$*$ Transition range (run out) \\
\hline
\end{tabular}

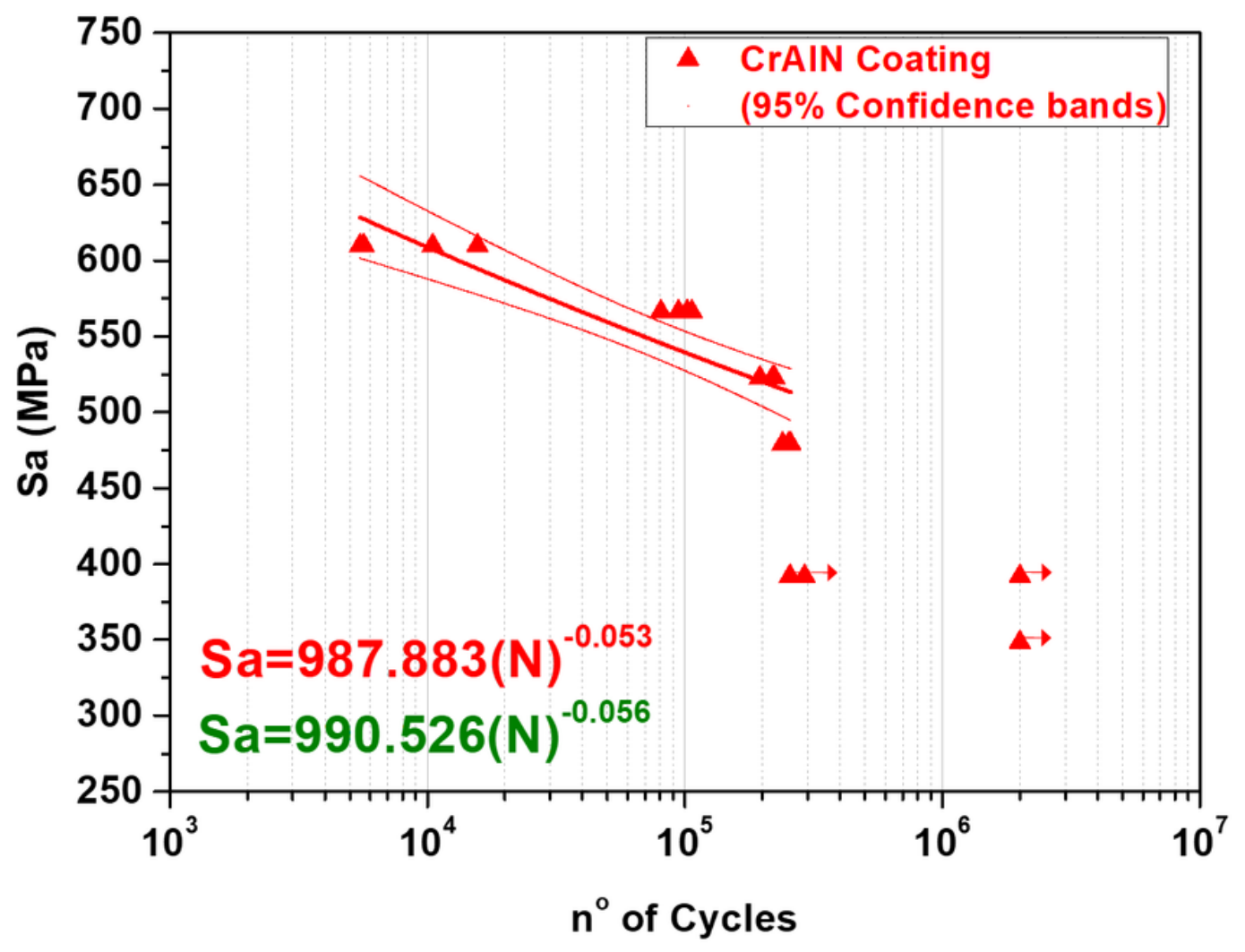

Figure 8

Maximum alternating tension ( $\mathrm{Sa}$ ) as a function of the number of failure cycles $(\mathrm{N})$ for CrAlN-coated steel. 


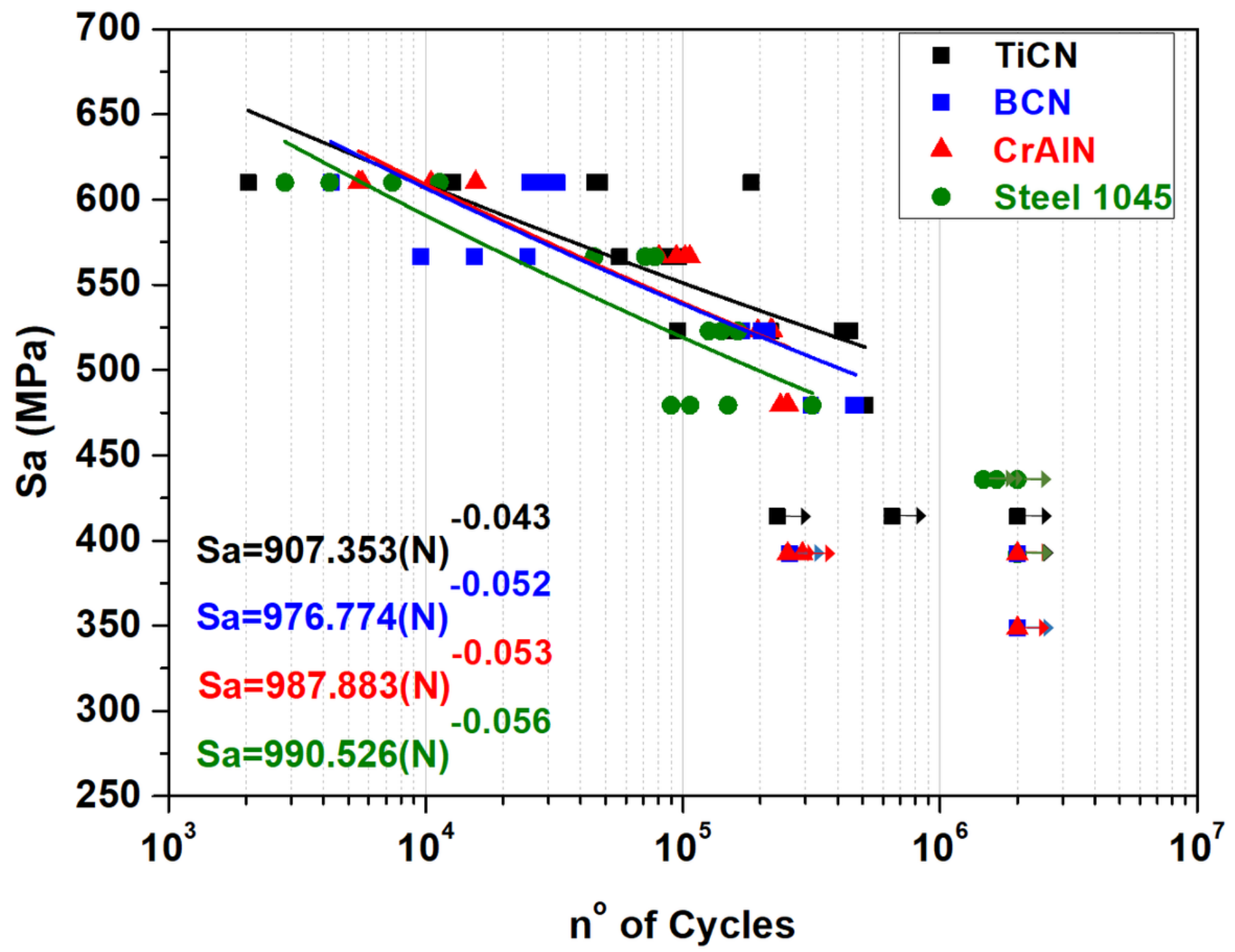

Figure 9

Full graph of the maximum alternating tension $(\mathrm{Sa})$ as a function of the number of failure cycles $(\mathrm{N})$ for the uncoated and coated samples (TiCN, BCN and CrAIN). 

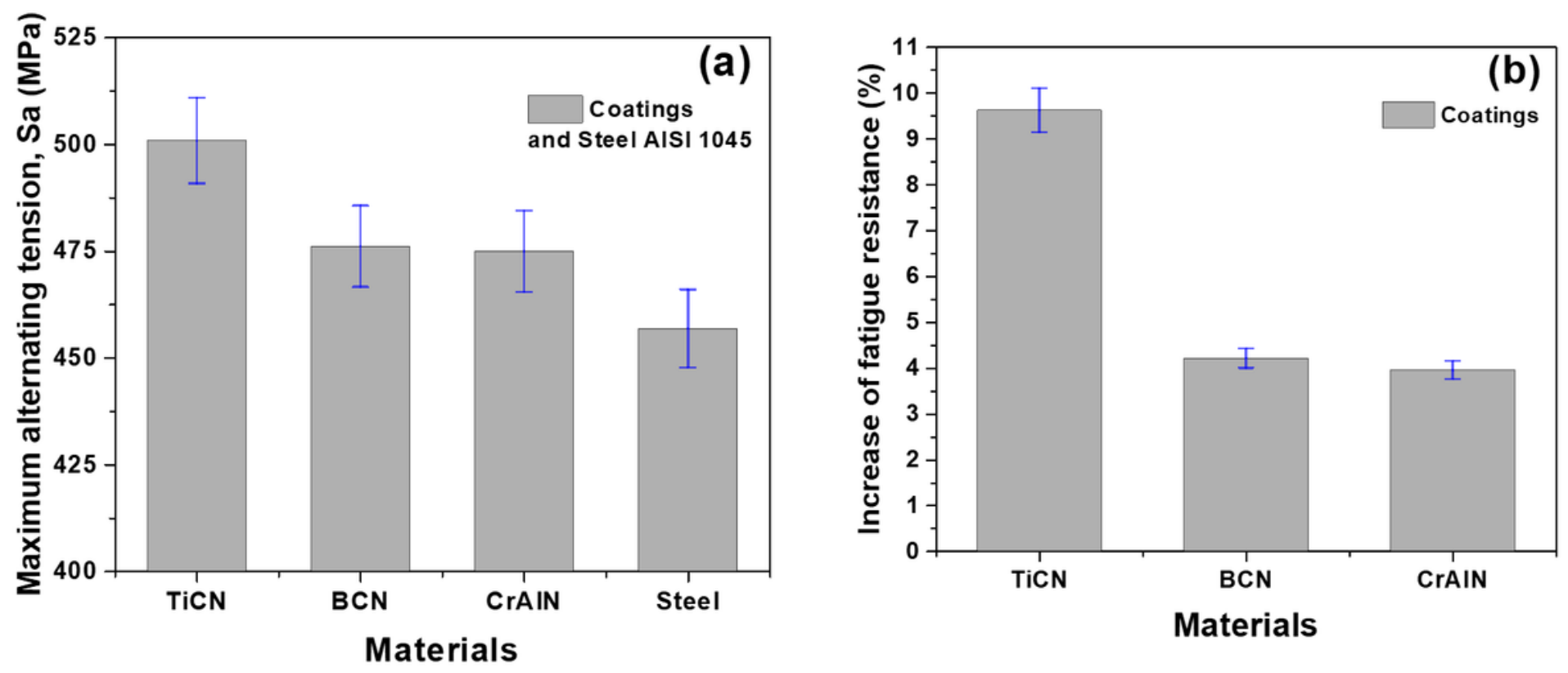

Figure 10

(a) Increase in maximum alternating tension as a function of the materials, (b) Increase of fatigue resistance as a function of the type of coating (Material). 

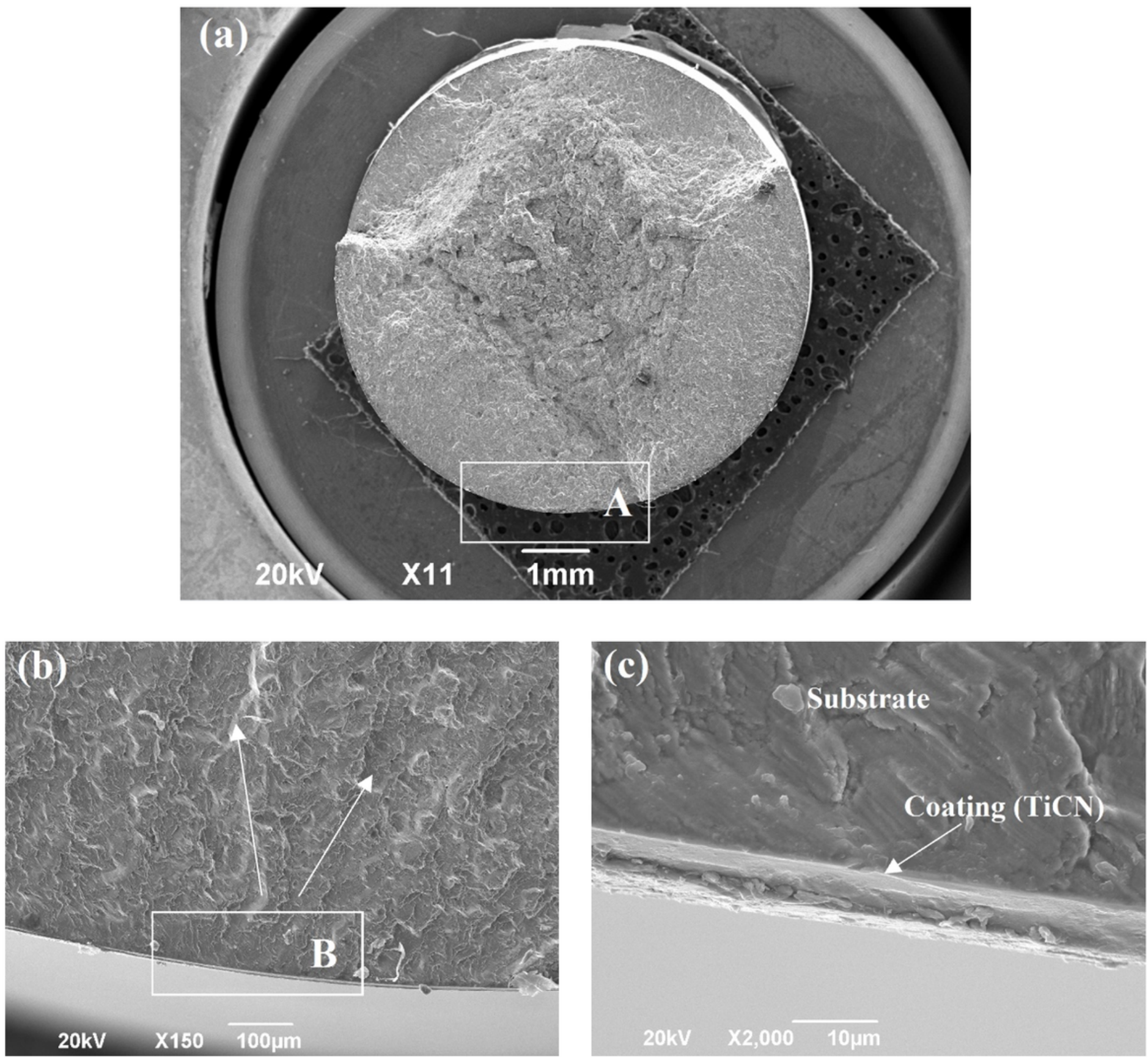

\section{Figure 11}

(a) Fracture surface of a TiCN-coated sample tested at $610.137 \mathrm{MPa}(70 \%$ Sut) and which failed at 45422 cycles, (b) magnified view of the area identified in square (A), the direction of crack propagation is clearly visible by the arrows, and (c) detailed view of the area identified in square (B), the final fracture and crack initiation site can be observed. 

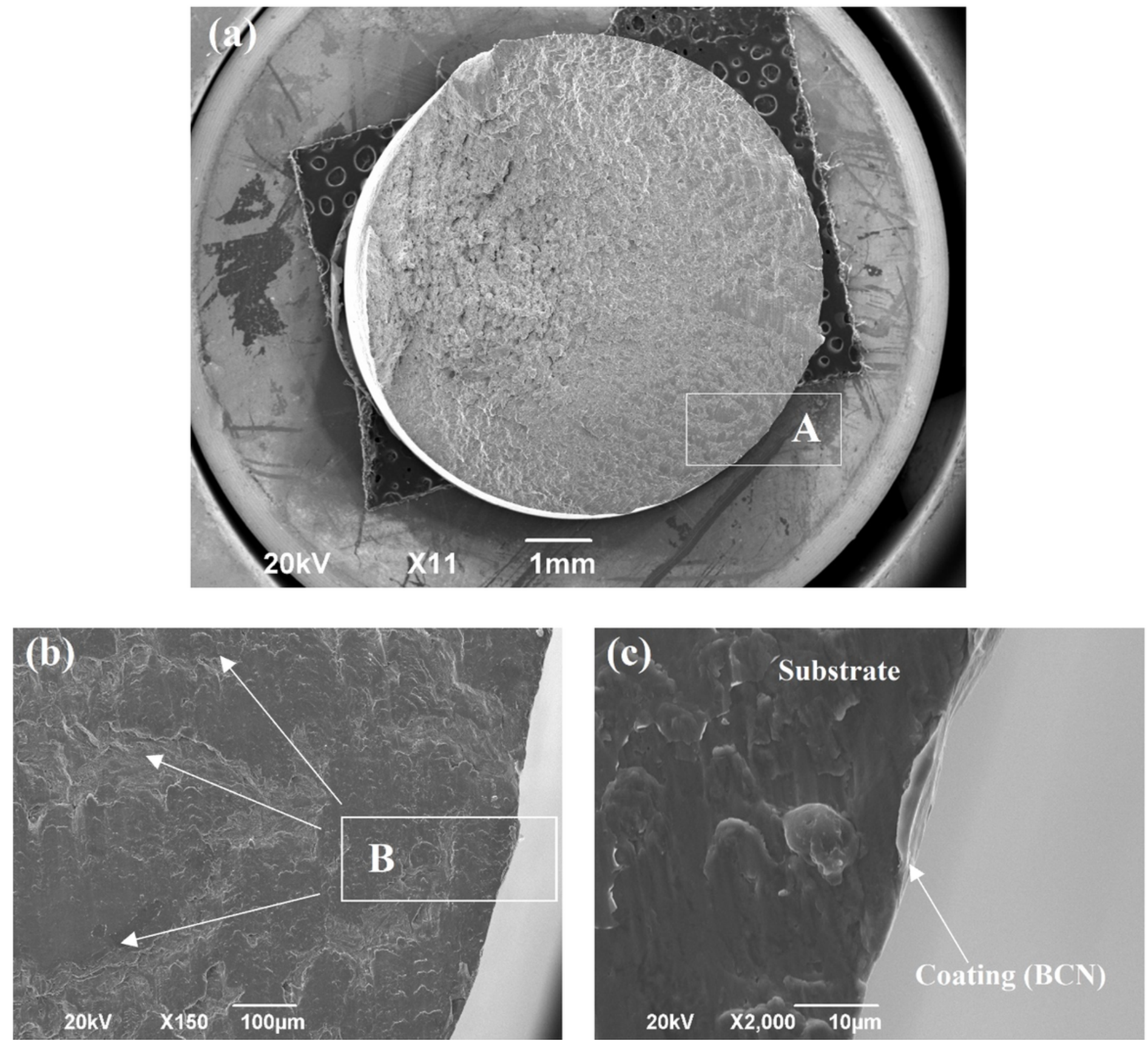

\section{Figure 12}

(a) Fracture surface of a BCN-coated sample tested at $610.137 \mathrm{MPa}$ (70\% Sut) and which failed at 28428 cycles, (b) magnified view of the area identified in square (A), where the direction of crack propagation is clearly visible, and (c) partial delamination of the coating is shown where the crack possibly nucleated from the square $(B)$. 

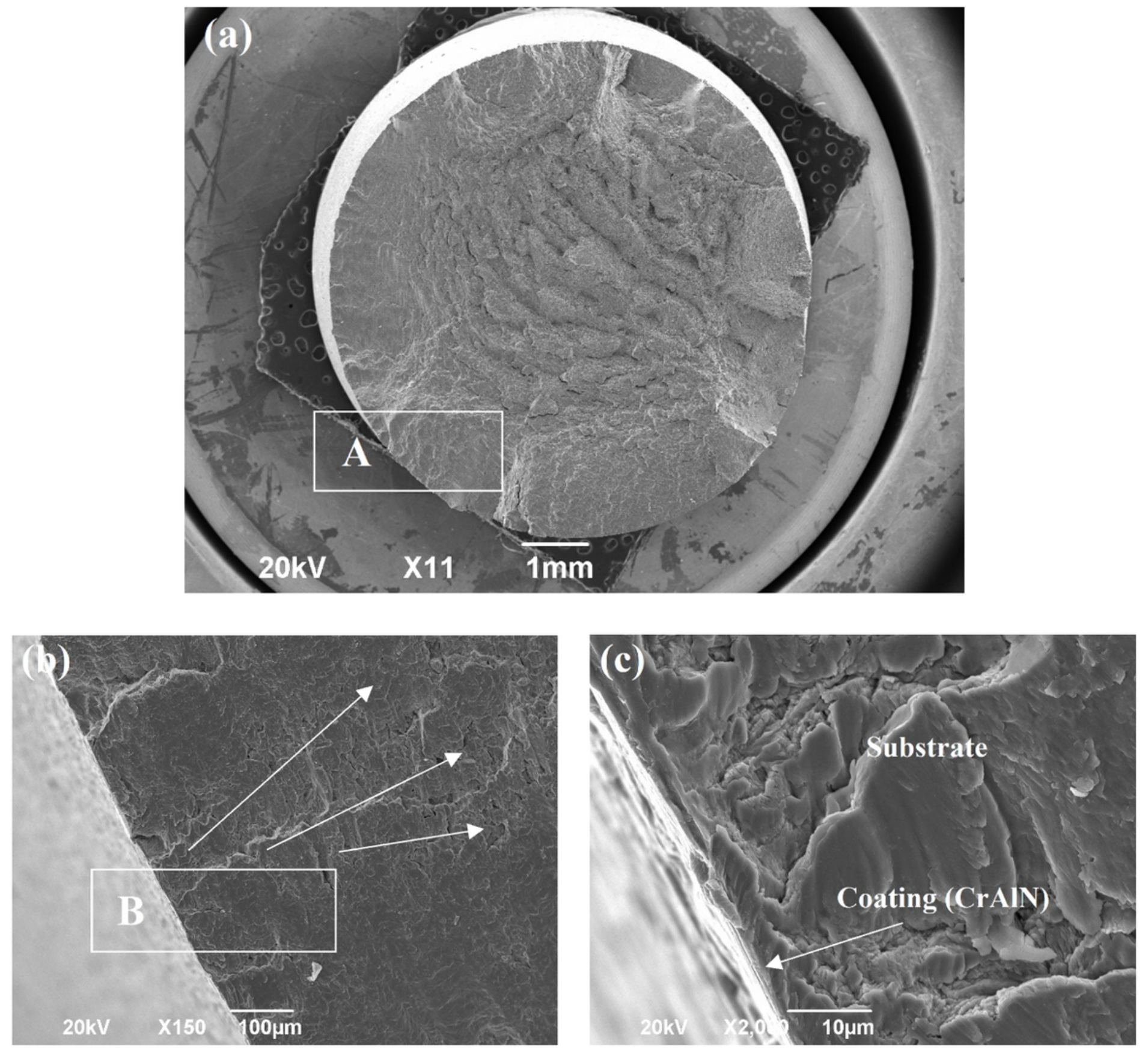

\section{Figure 13}

(a) Fracture surface of a CrAlN-coated sample tested at $610.137 \mathrm{MPa}(70 \%$ Sut) and which failed at 10482 cycles, some secondary cracks can be observed on the fracture surface, (b) Enlarged view of the area identified in square $A$, the direction of crack propagation is indicated by the arrows, and (c) Detailed view of the area identified in square (B), crack initiation site. 

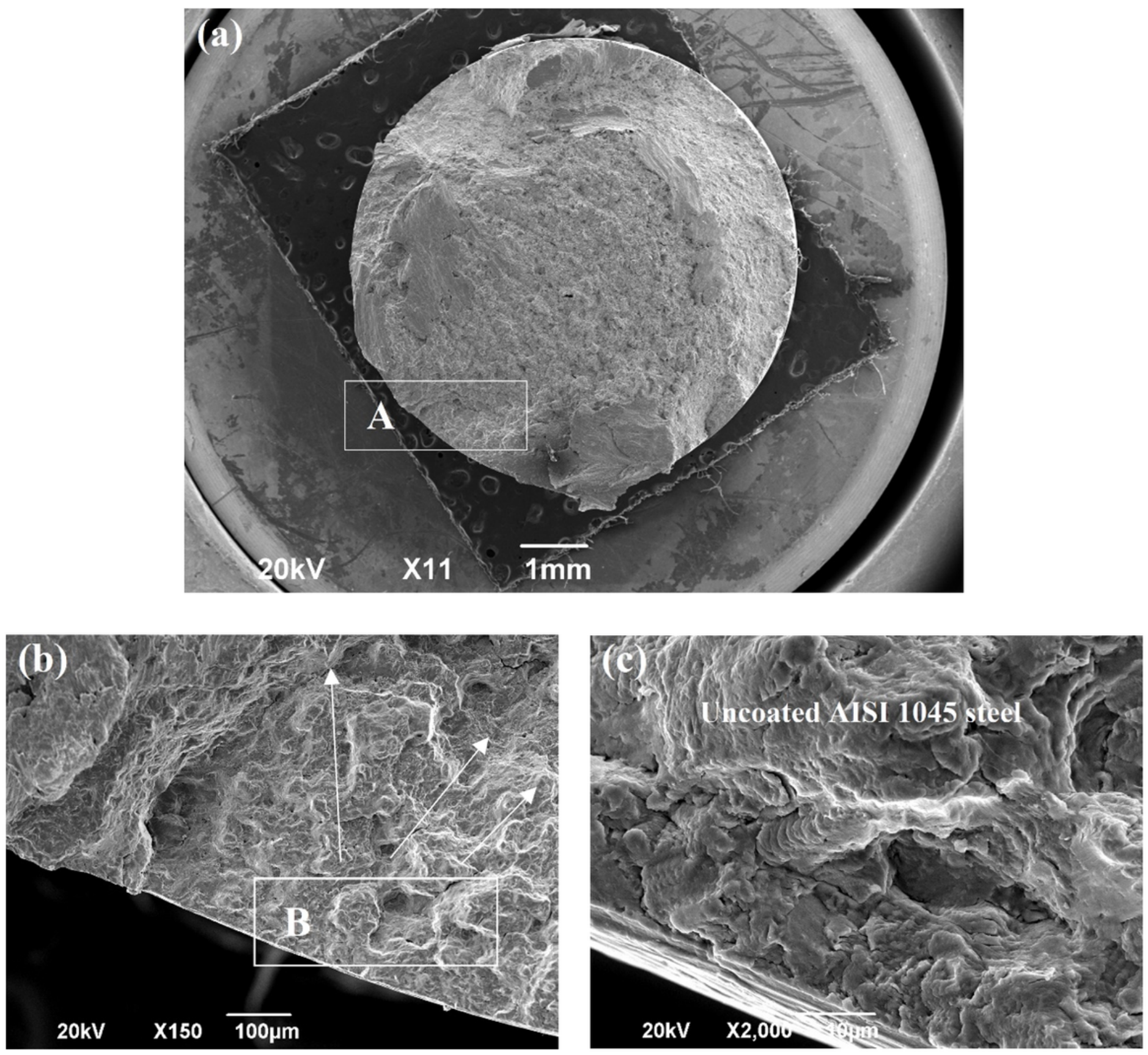

\section{Figure 14}

(a) Fracture surface of an uncoated AISI 1045 steel sample tested at $610.137 \mathrm{MPa}$ (70\% Sut) and which failed at 11312 cycles, (b) Enlarged view of the area identified as A, the direction of crack propagation is indicated by the arrows and (c) Detailed view of the area identified in square (B), possible crack nucleation site. 

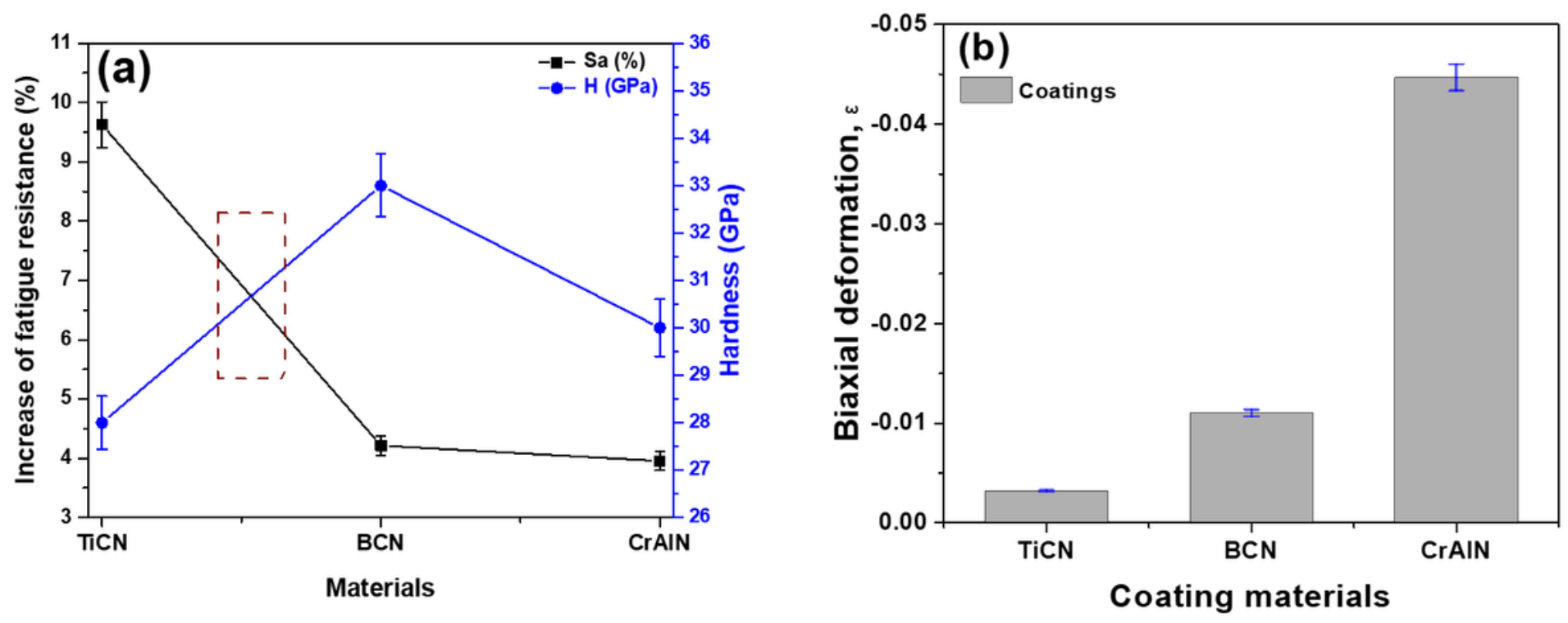

Figure 15

(a) Correlation between mechanical and fatigue properties for the TiCN, BCN, and CrAIN coatings deposited as a function of the coating nature, (b) Biaxial deformation as a function of the coating material. 